NASA Technical Memorandum 82712

AIAA-81-1991

\title{
An Improved Prediction Method for Noise Generated by Conventional Profile Coaxial Jets
}

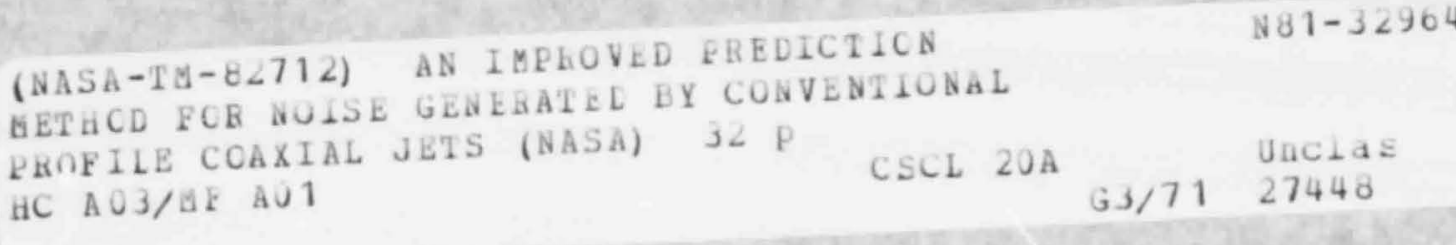

James R. Stone, Donald E. Groesbeck, and Charles L. Zola Lewis Research Center Cleveland, Ohio

Prepared for the

Seventh Aeroacoustics Conference

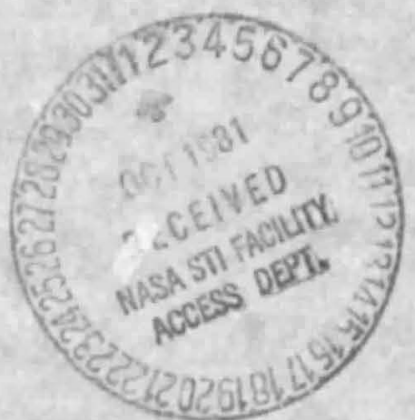
sponsored by the American Institute of Aeronautics and Astronautics Palo Alto, California, October 5-7, 1981 


\author{
James R. Stone, "Uonalo E. Groesbeck, *" \\ and Lharles L. Zolat
}

\author{
Matiolial Aeronautics ano Space Aaministration \\ Lewis Research Center \\ Cleveland, Unio 44135
}

\section{Aostract}

\begin{abstract}
A semi-empirical model for predicting the noise generated by conventional-velccity-profile jets exhausting trom coaxial nozzles is presented ano compared with small-scale static and simulated flignt oata. The present method is an upoated version of that part of the original NASA Aircraft Noise Prediction (ANUP) Program (1974) relating to coaxial jet noise. That methoo has been shown to agree reasonably well with model and full-scale experimerital data except at high jet velocities in the region near the jet axis. Improvements to the basic circular jet noise preoiction have been developed since that time which improve the accuracy, especially at nigh jet velocity and near the jet axis, and are incorporated into the coaxial jet procedure in this paper. The new procedure is more theoretically basea and has also been inproved by some empirical adjustments.
\end{abstract}

\section{Introduction}

Accurate noise prediction methoos are required in order to predict the environmentai lilpact of airport operations on the surrounding communtiles, as well ds tur the redistic design ut hew dirurat dilu lie development of noise re-

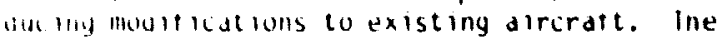
mrulchlon mellow presentes nerein is an upuated, Hiere theoretically odsed, version of that part of llie urigind IMASA Alriratl Noise prealction pro4"anl pertalling to cuadal nuzzles with convenilund velocity profiles (e.g. inner-stream velucity greater than outer stream velocity). lills paper uedis only with the nolse generdted by the exhaust jets mixing with the surrounding air dold wees not comsluer other moises emandting tron the englite such as narruw-band shock screech or interndlly-geilerdede nulse's.

Al though the hullerous aspects of the llechanisills of nolse generdtion by codxid jets are not tully understoou, the necessily of redicting jot noise has led to the development of empirical procedures. The NASA interin prealction method for jet noisel and several jifterent methods based on extension of the sociely of Automotive ting . neers (Sat) metnou tor circular jets are in current use. Ine NASA interim method has already been shown to dyree redsunably well with mudel ano full-scale static and tight vata 3 for low to moderately-nigh bypass ratio codxial jets. Inis interim lietnod is bases on a circular jet method (also in ket. 1) which is accurate only up to jet velocities of about $b 20 \mathrm{~m} / \mathrm{sec}$; however.

Thedu, Section $A$, Jet Acoustics branch, AlaA Member.

- Kesearch tnyineer, jection $A_{\text {, Jet Acoustics }}$ branch.

Thesedrch tngineter. Mission Analysis Otfice, Al AA Member. that circular jet methou has since been improved by incorporating a more theoretically justified formulation of source convection effects. 4 The oesirability of furtner minor improvements in th circular nozzle prediction of static airectivity and spectra near the peak noige angle was shown by the comparisons of Gutierrez.5 it is desirable, therefore, to incorporate the improved convection formulation in the conventional velocity-profile coaxial jet mixing noise prediction procedure, along with the empirical improvenents motivated by the comparisons of Ret. 5 and some minor changes in the treatment of tlight effects.

For the case of supersonic primary (innerstrean) andor seconodry (outer-stream) jets, urcadband snock/turbulence interaction noise must also de considered. The purely empirical shock nuise methoo of Ref. 1 is replaced in the current methoo by an extensive of the semi-empirical metnod developed in Ref. 4 for circular jets, which is Dased largely on the theory of Harperbourne and $F$ isher. 6

The tormulations of these predictions for jet mixing and shock noise are presented in this paper. The validity of these improved predictions is established oy fairly extensive comparisons with model-scale static data. Insufticient appropriate simulated-t light oata are available in the literature so verification of flight effects must be deterred.

\section{Symools}

(All aimensions are in SI units unless noted.)

\begin{tabular}{|c|c|}
\hline$A$ & ared \\
\hline$c$ & speed of sound \\
\hline u & nuzzle hyuraulic aldmeter \\
\hline $\mathrm{F}$ & tunctional relation (EQ. (4)) \\
\hline fs & $\begin{array}{l}\text { trequency shitl parameter veflined in } \\
\text { Eq. (3) }\end{array}$ \\
\hline 1 & $1 / 3$-octave-banu center irequency \\
\hline m & Mach number, $V / c$ \\
\hline III & texponent detined in Eq. iL) \\
\hline UASPL & $\begin{array}{l}\text { overall suunu pressure level, } \\
\text { co re } c 0 \mathrm{mN} / \mathrm{m}^{2}\end{array}$ \\
\hline D & pressure \\
\hline k & source-to-observer distance \\
\hline $\mathrm{s}$ & eftective strounal number \\
\hline$S H L$ & $\begin{array}{l}\text { 1/3-octave-band sound pressure level, } \\
\text { ab re } \mathrm{CU} \mathrm{m} / \mathrm{nk}^{2}\end{array}$ \\
\hline 1 & total temperature \\
\hline UOL & $\begin{array}{l}\text { predicted UASPL uncorrected tor retrac- } \\
\text { thon, do re } 20 \mathrm{uN} / \mathrm{m}^{2}\end{array}$ \\
\hline v & velocity \\
\hline $\mathbf{r}$ & $\begin{array}{l}\text { min imum (perpendicular) distance of } \\
\text { observer trom engine axis (Fig. 1), deg }\end{array}$ \\
\hline a & $\begin{array}{l}\text { Jet angle of diack (tig. } 11,0 \text {, } \\
\text { ilight level relative to static, } O B\end{array}$ \\
\hline ? & vensity \\
\hline
\end{tabular}


- pular angle from inlet axis (fig. 1), deg

- ettective polar angle, $\left(V_{j} / c_{a}\right) 0.1$, deg

OM Mach angle, $180^{\circ}-\sin ^{-1}\left(1 / A_{J}\right)$, deg

- azimuthal angle (fig, 1), deg

- mouitied (aircratt) uirectivity angle

(Fig. 1), aeg

* Uensity exponent (Eq. (ALO))

Subscripts:

\begin{tabular}{|c|c|}
\hline d & ambient or apparent \\
\hline c & convection \\
\hline $\mathrm{u}$ & dynamic \\
\hline e & effective \\
\hline$\vec{f}$ & t light \\
\hline ISA & $\begin{array}{l}\text { international standara atmospnere (288 } \\
\left.\text { and } 101.3 \mathrm{kN} / \mathrm{m}^{2}\right)\end{array}$ \\
\hline 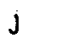 & 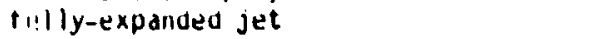 \\
\hline k & k inenlatic \\
\hline $\begin{array}{l}s \\
\text { yu } \\
u^{*}\end{array}$ & $\begin{array}{l}\text { shock noise } \\
\text { parameter evaluateo at } 0=90^{\circ} \\
\text { dircratt }\end{array}$ \\
\hline 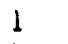 & tully-expanued primary (inner) jet \\
\hline & tully-expanued secondary (outer) jet \\
\hline
\end{tabular}

\section{Furillu lation of Proceuure}

The output of this prediction procedure is an array of SPL spectrad each angle of interest. (Acoustic power relations are not given explicitly, but power cumputatiuns may be made by integrating the results numerically over all angles.) The procedure calculates the spectra for snocktree jet mixing noise. including the eftects of tlight. Then, iupersonic jet shock noise eftects (static anu tignt) are calculated separately and doded antilogaritmically to the snock-tree jet III 1 ing spectra. The jet mixing noise and shock noise are assumed to be symmetric about the jet dxis. The geometric variables describing the position of the ouserver relative to the engine are snown scheinatically in fig. 1 . The noise levels preacted are tree-tiela (no retlections). tar-tiela ans lossless (i.e., the ettects of atmospheric aosorption are not included).

txperinental noise measurements are often mave di a distance tar enough fron the sources to be in the dicustic iar-tleld of each inulvidual source, but nut tar enuugh away to treat the ellire jet plune as a point source at the center ot the nozzle exit plane. When such is the case, comparisuns uetween experimental uata anu preaiction must take source locations into account. The methous used to approx mate these source location eftects for jet mixing ana shock nuise are those of ket. 4, using primary jet conditions. The source position is assumed to de at a primary noz$z$ le ulaterers downstream of the primary exit for a arectivity angle, $\theta$, of 0 vegrees dilu to vary linearly will $\theta$ to o primary diameters at $\theta$ - I8u veyrees.

det Mxing Nolse?

ulsen ditu trieuman' correlated snock-tree coldat low codxial jet nolse data for seconuary-toprillary jet velucily ratios, $V_{c} / V_{1}$. Irom U.L to 1.0 dild secomary-lo-primary area ratios, Aclal. tron $0.0 /$ to 43.b. This correlation was baste un extension and moditication of the methus of willidils, et al.8. In the orlgind? NASA Airup interim prediction method for jet nulse, t the methug ut ket. I was muditieu and extended to account for the case of a heated, snock-tree primary jet. The appros sh developed in Ket. I and used herein is as follows: (1) the overall sound pressure level, UASPL, and spectra are related to those of the isolated primary jet by means of simple correlation factors; (2) the directivity is taken to be the same as for the isolsied primary jet, as indicated by the experimental data of Kef. $i_{;}$and (3) the effects of tlignt are taken to be the same as for the isolated primary jet, as verified in Ref. 3. The prediction methodology is illustrated by a flow cnart in Fig. 2. The reouired inputs are shown at the top of the chart, followed by the logic for calculating the jet mixing noise (single or dud stream) and shock noise (for either one or two streams). The equations, figures and table requireo at each step are identified. The result is a tabulation of SPL spectra and UASPL as a runction of angle.

UUL. - The effects of area ratio, velocity ratio anu temperature ratio on the UASPL uncorrected for refraction, UUl., taken from Ref. 1 , are snown in Fig. 3, where the UUL relative to lind of the isolated primary jet, corrected for temperature ratio,

$$
U U L-U U L_{1}-10 \log \sqrt{\frac{T_{1}}{T_{2}}}
$$

is plotteo ayainst an area ratio parameter for various velocity ratios. The temperature ratio term is an einpirical approximation. The curves shown correspond to the recomended relation (moditieo tur temperature ratio from Ref. 7).

$$
\begin{aligned}
U U L-U U L_{1} & =b \log \left(\frac{I_{1}}{T_{2}}\right) \\
& +10 \log \left[\left(1-\frac{V_{2}}{V_{1}}\right)^{m}+1.2 \frac{\left(1+\frac{A_{2} v_{2}^{2}}{A_{1} v_{1}^{2}}\right)}{\left(1+\frac{A_{2}}{A_{1}}\right)^{3}}\right]
\end{aligned}
$$

In Eq. (1). UUL I is the UASHL uncorrected for retraction for the isolated primary jet calculated truin the relations given in dppenaix $A$, which is Dased on Ket. 4. The exponent $m$ is given by

$$
\left.\begin{array}{l}
\text { in }=1.1 \sqrt{\frac{A_{2}}{A_{1}} ; \frac{A_{2}}{A_{1}}}<2 y .1 \\
\text { iil }=0.0 ; \frac{A_{2}}{A_{1}} \geq 2 y .1
\end{array}\right\}
$$

The amolent temperature saca of kef. 7 are witnin approximately $* 2$ do of the curves snuwn, witn the greatest scatter at a velucity ratio, $V_{2} / v_{1}$, ot doout 0.0 .

spectra. - The shapes ot the sound pressure 
level spectra fur shock-free coaxial jets were generally found to be similar to tnose of the isolated prinary jet, out with the peak irequency snifted. 7 In Fig. 4 the effect of area ratio and velccity ratio on the frequency snitt paraneter, $F_{5}$, is shuwn, where

$$
F_{3}=\left(1-\frac{s_{1}}{s}\right)\left(\frac{1}{2}+\frac{\frac{T_{2} V_{2} A_{2}}{T_{1} V_{1} A_{1}}}{1+\frac{T_{2} V_{2} A_{2}}{T_{1} V_{1} A_{1}}}\right)^{-2}
$$

In Eq. (3), Si is the e: fective Strounal number for the isolated primary nozzle calculated from Appendix $A$, which is applicade to eitner a plug or circular cure nozzle, and the temperaturedependent terin is modified from that used in ket. I to provide proper limiting behavior. The previous formulation dio not include the influt ence of velocity ratio and area ratio on the tenperature effect, and it was limited to $T_{1} / T_{2}$ only sligntly less than 1.U. From Eq. (3) and fig. 4, the non-aimensionalized frequency ratio (coaxial to isulated primary). $S / S$, can de $c a l-$ culated, which gives the frequency shift relative to the isolated primary nozzle. The SPL(f) can inen de uutalieu fran Tade 1.

UASPL. - llle overall sound pressure level is udalned by integrdtilly the spectral results over the trequency range at interest.

Sllocin NoIse

The shock noise, for edach streall which is suersomic. is calculated separately by an extensin to thi' ircular jet methos developed in hi'. .4. it is assulled that there is no interacthis between the two streams. Ihat method was crolved Irentile model of Harper-borne and tishe'r and the ixperinental results of beiner and Norum. $y$ line averdll suund pressure level uncorrected fur retrd tion, for either streant wlllell is supersunic, UUL, d, is given by

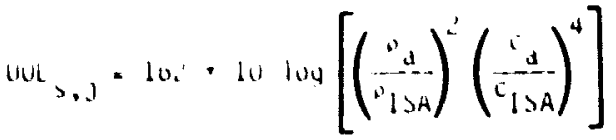

$$
\begin{aligned}
& \text { + } 10 \log \left(\frac{A^{2}}{k^{2}}\right)+10 \log \left[\frac{\left(M_{3}-1\right)^{2}}{1+\left(M_{3}-1\right)^{2}}\right] \\
& \left.-10 \log 11-m_{0} \cos +j+10-m_{m}\right)
\end{aligned}
$$

where is the angle of the observer relative to the direction of aircraft inotion, the Mach angle is given by $\theta_{M} \cdot 180^{\circ}-\sin ^{-1}\left(1 / M_{J}\right)$. dllu the subscript $j=1$ refers to the

primary (inmer) stream and $j=$ i reters to the secondary (outer) streain. Ine function $f$ is given oy

$$
\begin{aligned}
& t=0 \text { ior } 0 \leq \theta_{M} \\
& t=-0.10 \text { ror } 0>\theta_{M}
\end{aligned}
$$

The appropriate nolloimensional trequency paraneter, again based on the Harper-borne and fisherb inodel, is given by

$$
\begin{aligned}
& s_{s, j}=\left(\frac{f u_{j}}{0 . T V_{j}}\right) \sqrt{m_{j}^{2}-1}\left(1-m_{0} \cos \nu\right) \\
& \times \sqrt{\left[1+0.7\left(\frac{v_{j}}{c_{a}}\right) \cos \cdot\right]^{2}+0.0146\left(\frac{v_{d}}{c_{a}}\right)^{2}}
\end{aligned}
$$

where $u_{j}$ is the nyoraulic aiameter. Note that the convection velocity factor is 0.7 , instead of the 0.62 value used for jet mixing noise, but the 0.2 value of the turbulent length scale ratio is retalned, which leads to the 0.0196 factor. The shock noise peaks at $S_{S} j-1.0$ and varies with $l 0 g$ $S_{s, j}$ as shown in flg. 5. The SPLs,j as a function of trequency is inen determlned from $F i g . b$. where $S_{5, j}(f)$ is obtained from $E q .(5)$. Some effects of jet temperature and directivity angle on spectra! shape ano level have been observed by von Glannlo and others for circular jets, and perhaps such effects are also applicable to coaxial jets, but they are not presently included. Snock noise is not projected to be a tactor for future high-bypass engines, since both the jet stream conditions are subsonic at taheort dils lanuing.

\section{Comparisons with Experimental vata}

In is section contains limited comparisons of the present preaction metnod with experimental data for movel coaxlal jets. Although there exists d gredt ded of ducitional experimental uata with which comparisons may eventudlly be lilude, the present comparisons are considered to be sutticlent to vemonstrate the valiolty of the procezure. colildarisuns with comical nozzle vata dre presented in appenuix a to illustrate the valioity or the conical nozzle basis fur the present method.

\section{Static let Pliting Nuise}

Mulliple sideline jet noise measurements were outalled by coodykounti, el al. 11 tor a series at tour codxial nozzles naving secondary to primary area ratios. A $/ A$ l. trom 1.2 to 3.6 and a cumun primary nozzle diameter of $10.0 \mathrm{im}$. Vata. were obtalled at slueline distances of 1.l, 3.0. 2.0 and $1.0 \mathrm{~m}$. Iypical mult iple sideline oda aujusted to a comion sivellile uistance $(3.0 \mathrm{~m})$ ano correcteu for source pusition as described under furmulation ut procedure dre shown in $\mathrm{Fig}$. O for the 1.9 area-ratio coptanar codxial nozzle. Also shown dre predictions trom the present method and ind of ket. 1. At low trequencies the greater siaeline uistances appear to proviue more accurate experimental data as evidenced oy the relatively snwoth spectrd anu the generally good agreement with the present prediction. Similar results were ubtaineo for the smalier area ratios (not shown) dind for the conical nozzle case (shown in Appendix A). Inis result is consistent with the expectation that the low trequency noise producing region is aistributed for several dianeters jownstream of the jet exit. so that relatively large distances are reguires to reach the geometric far-tiela. At nigh trequenc les, there is an apparent ly anoma lous reversal of slope which is worse at large propaga- 
tion distances. Inis accentuation of anomalous Dehavior at large diztances is not unexpected, since at large distances the corrections for atmospheric attenuation are large and nonilinear propagation effects might become important. It is also clear that except for angles near the jet axis, the $5.0-m$ sideline $\left(Y / U_{1}-50\right)$ data are of good quality, and it is the experimental oata from this array which will be used for the remaining comparisons shown in this section.

In aduition to demonstrating the quality of the valioation data, tnis tigure shows how the present prediction compares with Ref. I at primary high jet velocity. (uifterences are smaller as $v_{1}$ decreases.) The imrovement due to the present method for angles uf $125^{\circ}$ and less is clear. However, at $>145^{\circ}$, the superiority of the new method is cTear only at low frequency; furthir improvements may be neeceo. The method of Ref, 1 gave excessively high levels at large angles, which gave unrealistically high nuratin. "ilties in effective perceived noise level cal, $1:$ ions, and that problem has been resclved in tile present metnod.

OASPL. - Sideline directivity patterns for each ñzzle contiguration are shown in Fig. 7 . In each case, the secondary conoitions are helo essentially constant at $V_{2}=215 \mathrm{~m} / \mathrm{sec}$ ano $T_{2}$ - $279 \mathrm{~K}$, ano the primary conditions are varied widely. It can be seen that the prediction method is reasunably dccurate in predicting the nolse directivity for this wide range of innerstrean convitions. It call also be seen, by cont paring the results tor the various contigurations, that the eftects of area ratio dind of noncoplanar exits are preuicteo reasunably well. It is also signiticall that the prediction methou prosuces proper fimiting results as the velocity ratio, $V, / V_{1}$, and temperature ratio, $I_{1} / I_{1}$.

aproach unity. Not only voes the present prediction dyree with the experintental uata in this I milling idse, but it agrees better with these wata trian does the noise predicted (Appendix A) for a silnglesestriali circular nozzle operding at the equivalent inleed-tlow conultions (velocity. temperature dilu llidss fluw rate). The stanuaro ueviation of the prealithon method with respect to tilis datd bet is 1.8 uo, and the averdye aver. previction is 0.5 vo. Uata for the other slaeline distances (not shuwn) show similar agreement.

spectra. - spectral comparisons fur these sdille conditions are shown in figs. 8 to 11 , for ured ratios of $1.2,1.4,1.9$ and 3.2 , respectively. In each case, spectral comparisons are shown it uirectivity angles of $45^{\circ}, 90^{\circ}, 165^{\circ}$ and $145^{\circ}$. Generdlly the dareement is good except at high treque les near the jet dxis: however, this probleil appedrs to ve partially with the experimental datd, ds uiscussev earlier in reterence to fig. 6 , rather than only with the prediction, but further stuoy of this issue appedrs justitied. There is some tenuency to overpredict the luw-trequency noise and underpredict the high-frequency noise for the case where the conditions of the two stredins approdch equality. Inis problem is not a major one however. since the inteurated measure, uverall sound pressure level, is reasonably accurate, dnu this is nut a cabe of interest tor red engine cycles.

\section{Shock Noise}

While snock noise is not likely to be signif icant tactor for future nigh-bypass engines, it should be included for generality and for the predictions of the noise for older. lower bypass engines and possible future supersonic transport engines. Inerefore, limited directivity and spectril comparisons with the static experimental results of Kef. 11 at supersonic primary conditions are included.

UASPL. - Sideline directivity patterns are snown in fig. 12 for coaxial nozzles having area ratios of 1.2, 1.4, 1.9, and 3.2 and a primary nozzle diameter of $10.0 \mathrm{~cm}$. In each case, the secondary conditions are held essentially constant at $v_{2}=216 \mathrm{~m} / \mathrm{sec}$ and $T_{2}=278 \mathrm{~K}$, and the primary conditions are varied. At a fullyexpandeo primary Mach number $M_{1} \cdot 1.4$, two cemperatures, $T_{1} \cdot 1130 \mathrm{~K}(\mathrm{~F}$ ig. $12(\mathrm{a}))$ and bUU K (Fig. $1 C(D))$, were tested, producing primary jet velocities $V_{2}=790$ ana $570 \mathrm{~m} / \mathrm{sec}$. Kesults are also snown in Fig. $12(\mathrm{c})$ for a lower Mach number, M1 - 1.15, at $i_{1}=590 \mathrm{~K}$ and $V_{1} \cdot 490 \mathrm{~m} / \mathrm{sec}$. In eacn case the predicted snock noise is indicated by the dasn-dot curve, predicted jet mixing noise by the dashed curve and the tota; predicted noise by the solid curve. The high Mach number, ick temperature conditions have the strongest relative contribution of shock noise; this provides the most significant valication of the shock noise prediction, and the agreement is yood. At the low Mach number, there is an overprediction of total noise, especially for the large area ratio, which will be turther viscussed on a spectral basis in the tollowing section. The comparisons at high Mach number inuicate not only that the level of shock noise is prealcted reasunably well, Dut that the mixing noise levels are predicted reasonably well even in the presence of shocks in the flow tield. specitically for the high Mach number. the standaru veviation is $1 . y$ ab and the average overprediction is $0.6 \mathrm{~dB}$, about the same as in the subsonic case.

Spectra. - spectral comparisons for these salle conlutions are shown in Figs. 13 and 14, for the 1.2 and 3.2 area ratio nozzles, respectively. At the high Macn numuer, it appears tha: the shock noise is predicted reasonably accurately, and comparisons at the intermediate area ratios (not shuwn) are consistent with these results. For the large area ratio $(+19.1)$ the shock nolse at low mach number is overpredicted. In is very well coula be due to the large mass flow of the seconaary limpinging on the primary, causing an eftectively lower primary pressure ratio and Mach number. Pernaps the most important result of these comparisons is that the jet mixing noise prediction valiuity is demonstrated to an inner-stream jet velocity of at least $790 \mathrm{~m} / \mathrm{sec}$.

\section{flight titects}

The method presented herein was snown in Ket. IL Lu preaict the static-to-flight UASPL increnkents for jet mixing noise to within a standaru veviation of 1.5 do for full-scale tlignt tests. It woulo be desirable to show that the present method also agrees reasonably well with 
s imulated-flight model-scale results; however, no appropriate data are available in the optn itterature. Verification of flight effects must await the publication of suficicient simulatedflight oata, or alternatively, full-scale flight data may provide a better source of validation data.

\section{Concluding Remarks}

An improved semi-empirical model for predicting the noise generated by jets exhausting from coaxial nozzles with conventional velocity pro files is presented and compared with small-scale static and simulated-fight data. The prediction of jet mixing noise is based on the extensive experimental study and empirical correlation of 0 sen and Friedman (1974) for the effect of the secondary (outer-stream) relative to the isolated primary (inner-stream) jet. The isolated primary preoiction used as a base in an impreved NASA method for conical nozzles (1980). The effect of a primary nozzle plug is included in the prediction, but is not validated in the present paper. The snock noise for a supersonic primary is assumed to be unaffected by the secondary flow and is calculater from a model based on extension of the method of Harper-Bourne and Fisher (1973). The predictions formulated for both sources cover the full angular range from 0 to 180 degrees. There are no inherent limitations on the range of the prediction methods, and comparisons with static model data are presented for primary jet velocities ranging from 200 to $795 \mathrm{~m} / \mathrm{sec}$. These comparisons indicate that the overall sound pressure level is predicted within a standard deviation of $1.8 \mathrm{~dB}$.

\section{Appendix A}

Single-stream Jet Mixing Noise Prediction

\section{formulation}

The coaxial jet noise prediction presented nerein uses the noise of the nypothetical isolated primary jet as a builoing block. This appendix presents tnese primary jet relationships, which are Dased on Ref. 4, with ininor improvements and with the dadition of plug nuzzle ettect from Ref. 1. The overall sound pressure level, witnout correction fur refraction, $U L_{1}$, is given by

$$
\begin{aligned}
& U U L_{1}=141+i U \log \left[\left(\frac{o_{a}}{\rho_{1 S A}}\right)^{2}\left(\frac{c_{d}}{C_{I S A}}\right)^{4}\right] \\
& +10 \log \left(\frac{A_{1}}{k^{2}}\right)+10 \log \left(\frac{\rho_{1}}{\rho_{a}}\right)^{\omega}+10 \log \left(\frac{V_{e}}{C_{a}}\right)^{7.5} \\
& -10 \log \left[\left(1+M_{c} \cos \theta\right)^{2}+U .04 H_{c}^{2}\right] \\
& -10 \log \left(1-m_{0} \cos v j+3 \log \left(\frac{2 A_{1}}{\pi U_{1}^{2}}+\frac{1}{2}\right)\right.
\end{aligned}
$$

$$
\begin{aligned}
v_{e} & =v_{1}\left[1-\left(v_{0} / v_{1}\right) \cos a\right]^{2 / 3} \\
\omega & =\frac{3\left(v_{e} / c_{a}\right)^{3.5}}{0.6+\left(v_{e} / c_{a}\right)^{3.5}-1} \\
m_{c} & =0.02\left(v_{1}-v_{0} \cos a\right) / c_{a}
\end{aligned}
$$

The modified directivity angle, $\psi$, is angle of the odserver relative to the direction of aircraft motion. The aigle of attack, $a$, is the angle of the upstream axis of the jet relative to the direction of aircraft motion. For flyover directly over the observer, - - a. Spectral relationships are given in Table I, where SPL - UOL is giyen at various corrected angles, $0^{\prime}=\left(V_{1} / c_{q}\right) 0$.1 as a function of the logarithm of the effective Strouhal number. $S$. for the single stream case, $S \cdot S_{1}$, where

$$
\begin{aligned}
S_{1} & =\frac{t^{4 A_{1} T_{\pi}}}{V_{e}}\left(\frac{D_{1}}{\sqrt{4 A_{1} T_{\pi}}}\right)^{0.4} \\
& \times\left(\frac{T_{1}}{T_{a}}\right)^{0.4\left(1+\cos \theta^{\prime}\right)}\left[1-M_{0} \cos \theta\right]
\end{aligned}
$$

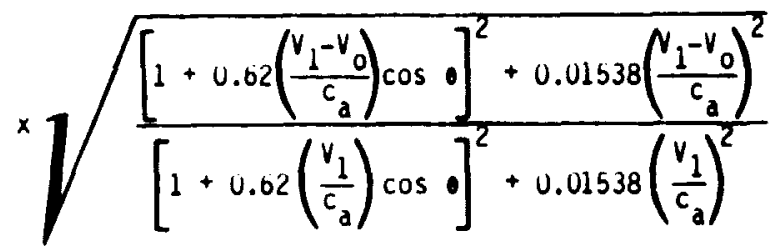

(A2)

Table I differs somewhat from that given in Ref. 4 , in order to produce a more accurate preaiction at the peak noise angle and near the jet axis, Dased on the comparisons of Gutierrez. 5

\section{Validation}

Since minor improvements have been made with respect to kef. 4, some of the comparisgns shown therein with the ada of Tanna, et al. 13 are repeated nere using the modified prediction. In adition, sing?e-stream results from the facility providing the ata used to validate the coaxial predictionll are compared with the single jet prediction.

In Fig. Al spectral comparisons with the data of ket. 13 are shown at directivity angles of 57 . 86,110 , and 155 degrees for jet velocities from U.8 to 2.b5 times the ambient sonic velocity. The agreement is reasondoly good. Furtner comparisons are made in Fig. A? with the data from various sideline distances $l 1$ for a coaxial nozzle with flow in the inner stream only. The agreement is quite similar to the coaxial results of $\mathrm{Fig} .6$. Ine comparsons snow that the conical nozzle static jet noise data from the same tacility which provided nost of the coaxial oata utilized herein is in agreenent witn the prediction. 


\section{Keferences}

1. Stone, J. R., "Interim Prediction Method for Jet Noise," NASA TM X-71618, 1974.

2. "Gas Turbine Jer Exhaust Noise Prediction," Society of Autonotive Engineers, SAE-ARP-870, Mar. 1978.

3. Stone, J. R., "Prediction of In-filght Exhaust Noise for Turbojet and Turbof an Engines," Noise Control Engineering, Vol. 10, Jan.-Feb. IY78, PD. 40-46.

4. Stone, J. R.. and Montegani, F. J., "An Improved Prediction Method for the noise Generated in Flight by Circular Jets," NASA TM-81470, 1980.

5. butierrez, 0. A., "Effect of Facility Variation on the Acoustic Characteristics of Three Single Strean Nozzles," NASA TM-81635, 1980.

b. Harper-Bourne, M., and Fisher, M. J., "The No ise from Snock Waves in Supersonic Jets," Noise Mecnanisins, AlaRU-CP-131, Advisory Group for Aerospace Research and Uevelopment, Paris, 1y73, DP. 11-1 to 11-13.

7. OIsen, W. A., and Friedman, R., "Jet Nolse from Coaxial Nozzles over a Wide Range of Geo- inetric and Flow Parameters," AIAA Paper 74-43. Jan. 1474.

ð. WHllians, T. J., All, M. R. M. H., ana Anoerson, J. S." "Noise and flow Cnaracteristics of Coaxtal Jets," Journal of Mechanical Engineering Science, Vol. 11. Apr. 19oy, pp. 133-142.

9. Seiner, J. M., and Morum, T. O., "Experiments on Shock Assoclated Noise of Supersonic jets," Alah Paper 79-1526, July 1979.

10. von Glahn U.. "New Interpretations of ShockAssociated Noise with and without Screech," MASA TM-81590, 1980.

11. Goodykoontz, J. H., and Stone, J. R., "Experimental Study of Coaxtal Nozzle Exhaust Noise." AIAA Paper 7y-0631, Mar. 197y.

12. Stone, J. R.. "An Improved Method for Predicting the Effects of Flight on Jet Mixing No ise," MASA TM-79155, 1y7y.

13. Tanna, H. K., Vean, P. U.. and Burrin, R. H., "The Generation and Radiation of Supersonic Jet iuise, Vol. III: Turbulent Mixing Moise Data," LG76EROJ 33-Vol-3, Lockneed-Georgia Co., Marietta, iA, 1970. (AL-AO32882, AFAPL-TR-76-65-Vol-3.) 
TABLE 1. - RECOMAENDED SPECTRA FOR JET MIXING NOISE

\begin{tabular}{|c|c|c|c|c|c|c|c|c|c|c|c|}
\hline \multirow{3}{*}{$\begin{array}{l}\text { Fre- } \\
\text { quency } \\
\text { paran- } \\
\text { eter. } \\
\log S^{\prime}\end{array}$} & \multicolumn{11}{|c|}{ Corrected directivity angle (referred to inlet), $\cdots=\left(v_{g} / c_{a}\right)^{0.1}$, degrees } \\
\hline & $\begin{array}{l}0^{\circ}- \\
110^{\circ}\end{array}$ & $120^{\circ}$ & $130^{\circ}$ & $140^{\circ}$ & $150^{\circ}$ & $160^{\circ}$ & $170^{\circ}$ & $180^{\circ}$ & $190^{\circ}$ & $200^{\circ}$ & $250^{\circ}$ \\
\hline & \multicolumn{11}{|c|}{ Normalized sound pressure level, SPL - UOL, dB } \\
\hline $\begin{array}{r}-3.6 \\
-1.8 \\
-1.7 \\
-1.6 \\
-1.5 \\
-1.4 \\
-1.3 \\
-1.2 \\
-1.1 \\
-1.0 \\
-.9 \\
-.8 \\
-.7 \\
-.8 \\
-.5 \\
-. .4 \\
-.3 \\
-.2 \\
-.1 \\
.0 \\
+.1 \\
. .2 \\
.3 \\
.4 \\
.5 \\
.6 \\
.7 \\
.8 \\
.9 \\
1.0 \\
1.1 \\
1.2 \\
1.3 \\
1.4 \\
1.5 \\
1.6 \\
1.7 \\
1.8 \\
3.6 \\
0 A S S L- \\
U 0 L \\
\end{array}$ & $\begin{array}{l}-85.0 \\
-40.5 \\
-38.0 \\
-35.6 \\
-33.3 \\
-30.9 \\
-28.6 \\
-26.2 \\
-24.0 \\
-21.8 \\
-19.5 \\
-17.5 \\
-15.9 \\
-14.7 \\
-13.7 \\
-12.8 \\
-22.1 \\
-11.6 \\
-11.3 \\
-11.1 \\
-11.2 \\
-11.3 \\
-11.7 \\
-12.3 \\
-13.0 \\
-13.7 \\
-14.6 \\
-15.6 \\
-16.7 \\
-17.8 \\
-18.9 \\
-20.1 \\
-21.3 \\
-22.4 \\
-23.6 \\
-24.8 \\
-26.0 \\
-27.2 \\
-48.8 \\
.0\end{array}$ & $\begin{array}{l}-90.0 \\
-40.4 \\
-37.8 \\
-35.4 \\
-33.2 \\
-30.9 \\
-28.6 \\
-26.2 \\
-24.0 \\
-21.8 \\
-19.5 \\
-17.4 \\
-15.6 \\
-14.0 \\
-12.4 \\
-11.0 \\
-10.2 \\
-9.9 \\
-10.2 \\
-10.6 \\
-11.1 \\
-11.8 \\
-12.7 \\
-13.7 \\
-14.7 \\
-15.8 \\
-16.9 \\
-18.0 \\
-19.2 \\
-20.4 \\
-21.6 \\
-22.8 \\
-24.0 \\
-25.2 \\
-26.4 \\
-27.6 \\
-28.8 \\
-30.0 \\
-51.6 \\
+.1\end{array}$ & $\begin{array}{l}-95.0 \\
-40.4 \\
-37.4 \\
-34.4 \\
-31.4 \\
-23.5 \\
-25.7 \\
-22.9 \\
-20.1 \\
-17.3 \\
-14.7 \\
-13.0 \\
-11.5 \\
-9.7 \\
-9.0 \\
-8.9 \\
-9.1 \\
-9.6 \\
-10.8 \\
-12.0 \\
-13.3 \\
-14.6 \\
-15.9 \\
-17.2 \\
-18.5 \\
-19.8 \\
-21.1 \\
-22.4 \\
-23.7 \\
-25.0 \\
-26.3 \\
-27.6 \\
-28.9 \\
-30.2 \\
-31.5 \\
-32.8 \\
-34.1 \\
-35.4 \\
-58.8 \\
+.5\end{array}$ & $\begin{array}{r}-100.0 \\
-40.3 \\
-37.1 \\
-33.8 \\
-30.3 \\
-26.8 \\
-23.4 \\
-19.8 \\
-16.2 \\
-13.2 \\
-11.2 \\
-10.2 \\
-9.5 \\
-8.8 \\
-8.1 \\
-8.4 \\
-8.9 \\
-9.8 \\
-11.3 \\
-12.9 \\
-14.5 \\
-16.1 \\
-17.7 \\
-19.3 \\
-20.9 \\
-22.5 \\
-24.1 \\
-25.7 \\
-27.3 \\
-28.9 \\
-30.5 \\
-32.1 \\
-33.7 \\
-35.3 \\
-36.9 \\
-38.5 \\
-40.1 \\
-41.7 \\
-70.5 \\
+1.1\end{array}$ & $\begin{array}{r}-100.0 \\
-40.1 \\
-37.0 \\
-33.5 \\
-30.0 \\
-26.4 \\
-23.0 \\
-19.4 \\
-16.8 \\
-14.5 \\
-13.1 \\
-11.0 \\
-9.4 \\
-8.3 \\
-7.7 \\
-8.3 \\
-9.8 \\
-11.6 \\
-13.4 \\
-15.2 \\
-17.0 \\
-18.8 \\
-20.6 \\
-22.4 \\
-24.2 \\
-26.0 \\
-27.8 \\
-29.6 \\
-31.4 \\
-33.2 \\
-35.0 \\
-36.8 \\
-38.6 \\
-40.4 \\
-42.2 \\
-44.0 \\
-45.8 \\
-47.6 \\
-80.0 \\
+.4\end{array}$ & $\begin{array}{r}-100.0 \\
-39.5 \\
-36.4 \\
-33.3 \\
-29.5 \\
-25.5 \\
-22.8 \\
-20.0 \\
-17.5 \\
-16.2 \\
-14.7 \\
-13.5 \\
-12.6 \\
-12.0 \\
-11.7 \\
-12.6 \\
-14.5 \\
-16.4 \\
-18.3 \\
-20.2 \\
-22.1 \\
-24.0 \\
-25.9 \\
-27.8 \\
-29.7 \\
-31.6 \\
-33.5 \\
-35.4 \\
-37.3 \\
-39.2 \\
-41.1 \\
-43.0 \\
-44.9 \\
-46.8 \\
-48.7 \\
-50.6 \\
-52.5 \\
-54.4 \\
-88.6 \\
-3.2\end{array}$ & $\begin{array}{r}-100.0 \\
-37.5 \\
-33.5 \\
-30.0 \\
-27.0 \\
-24.5 \\
-22.5 \\
-20.5 \\
-18.5 \\
-16.5 \\
-15.5 \\
-14.5 \\
-14.0 \\
-14.5 \\
-15.8 \\
-17.9 \\
-20.0 \\
-22.1 \\
-24.2 \\
-26.3 \\
-26.4 \\
-30.5 \\
-32.6 \\
-34.7 \\
-36.8 \\
-38.9 \\
-41.0 \\
-43.1 \\
-45.2 \\
-47.3 \\
-49.4 \\
-51.5 \\
-53.6 \\
-55.7 \\
-57.8 \\
-59.9 \\
-62.0 \\
-64.1 \\
-101.9 \\
-5.8\end{array}$ & $\begin{array}{r}-90.0 \\
-36.0 \\
-33.0 \\
-30.0 \\
-27.0 \\
-25.0 \\
-23.0 \\
-21.0 \\
-19.0 \\
-17.0 \\
-16.0 \\
-15.5 \\
-16.5 \\
-18.0 \\
-20.0 \\
-22.2 \\
-24.4 \\
-26.6 \\
-28.8 \\
-31.0 \\
-33.2 \\
-35.4 \\
-37.6 \\
-39.8 \\
-42.0 \\
-44.2 \\
-46.4 \\
-48.6 \\
-50.8 \\
-53.0 \\
-55.2 \\
-57.4 \\
-59.6 \\
-61.8 \\
-64.0 \\
-65.2 \\
-68.4 \\
-70.6 \\
-110.2 \\
-7.7\end{array}$ & $\begin{array}{r}-80.0 \\
-35.0 \\
-32.5 \\
-30.0 \\
-27.5 \\
-25.5 \\
-23.5 \\
-21.5 \\
-19.5 \\
-17.5 \\
-17.0 \\
-17.5 \\
-18.5 \\
-20.0 \\
-21.8 \\
-24.1 \\
-26.4 \\
-28.7 \\
-31.6 \\
-33.1 \\
-35.1 \\
-37.9 \\
-40.2 \\
-42.5 \\
-44.8 \\
-47.1 \\
-49.4 \\
-51.7 \\
-54.0 \\
-56.3 \\
-58.6 \\
-60.9 \\
-63.2 \\
-65.5 \\
-67.8 \\
-70.1 \\
-72.4 \\
-74.7 \\
-116.1 \\
-9.0\end{array}$ & $\begin{array}{l}-70.0 \\
-34.0 \\
-32.0 \\
-30.0 \\
-28.0 \\
-26.0 \\
-24.0 \\
-22.0 \\
-20.0 \\
-18.5 \\
-19.0 \\
-20.0 \\
-21.0 \\
-22.0 \\
-23.5 \\
-25.9 \\
-28.3 \\
-30.7 \\
-33.1 \\
-35.5 \\
-37.9 \\
-40.3 \\
-4 c .7 \\
-45.1 \\
-47.5 \\
-49.9 \\
-52.3 \\
-54.7 \\
-57.1 \\
-59.5 \\
-61.9 \\
-64.3 \\
-66.7 \\
-69.1 \\
-71.5 \\
-73.9 \\
-76.3 \\
-78.7 \\
-121.9 \\
-10.6\end{array}$ & $\begin{array}{l}-60.0 \\
-33.8 \\
-32.0 \\
-31.0 \\
-30.0 \\
-31.0 \\
-32.5 \\
-34.5 \\
-36.6 \\
-38.8 \\
-40.1 \\
-42.5 \\
-45.0 \\
-47.5 \\
-50.0 \\
-52.5 \\
-55.0 \\
-57.5 \\
-60.0 \\
-62.5 \\
-65.0 \\
-67.5 \\
-70.0 \\
-72.5 \\
-75.0 \\
-77.5 \\
-80.0 \\
-82.5 \\
-85.0 \\
-87.5 \\
-90.0 \\
-92.5 \\
-95.0 \\
-97.5 \\
-100.0 \\
-102.5 \\
-105.0 \\
-107.5 \\
-152.5\end{array}$ \\
\hline
\end{tabular}




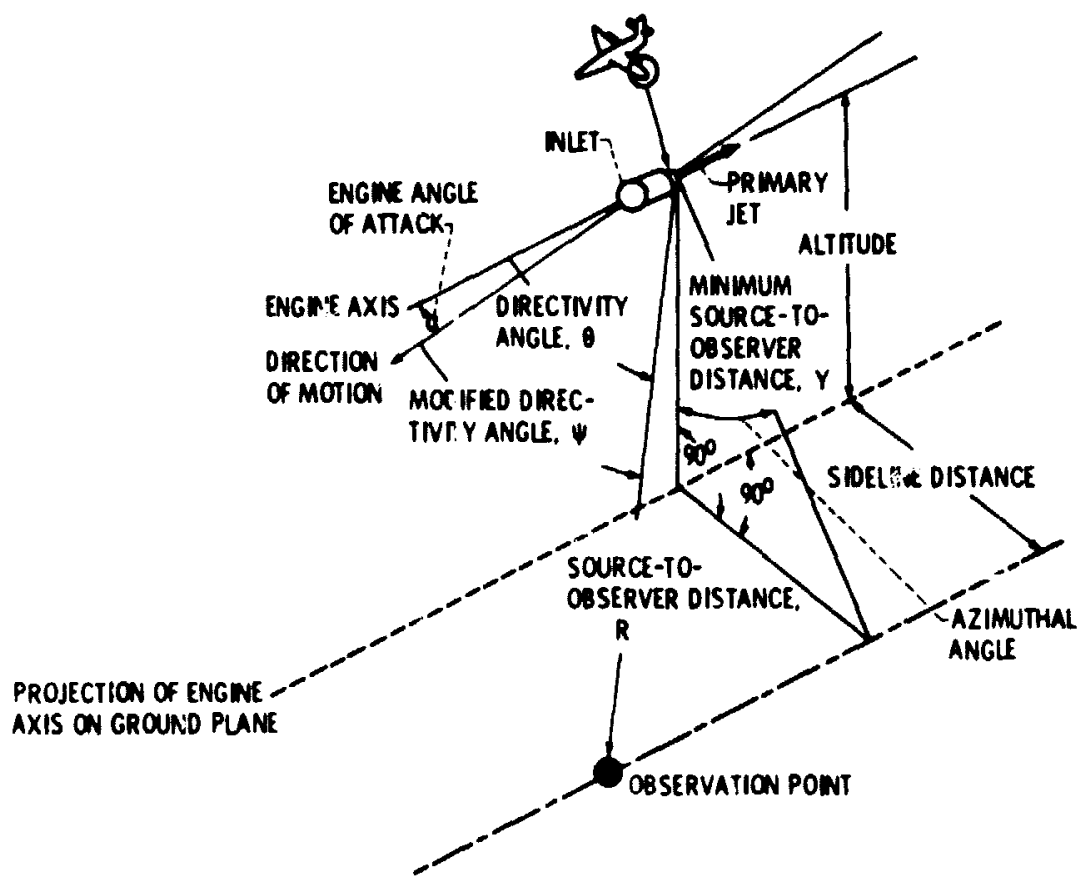

Figure L. Geometric varibbles describing position of airplane noise source with respact to an coservition point 


\section{NPUTS}

AMBIENT TEMPERATURE, $T_{1}$ AMBIENT PRESSURE, $P_{8}$ AIRCRAT VELOCIIY, $V_{0}$ ANGLE OF AT! $: X_{\text {, }}$ C
AzIMUTHAL ANGLE,

SOURCE-TO-OBSERVER DISTANCE, R PRIMARY TOTAL TEMPERATCRE, $T_{1}$
FREOUENCIES OF INTEREST, 1 FREOUENCIES OF INTEREST, I ANGLES OF INTEREST. $\theta$ PRIMARY ANWUAR HEIGHT, H (D) $/ 2$ FOR CONICALI
SECONDARY ET VELOCTY, V, SECONDARY TOTAL TEMFEATLRE, $T_{2}$ SECONOARY OUTER OUAETER, D, SECONOARY ANULA KEIGIT, $\mathrm{H}_{2}$

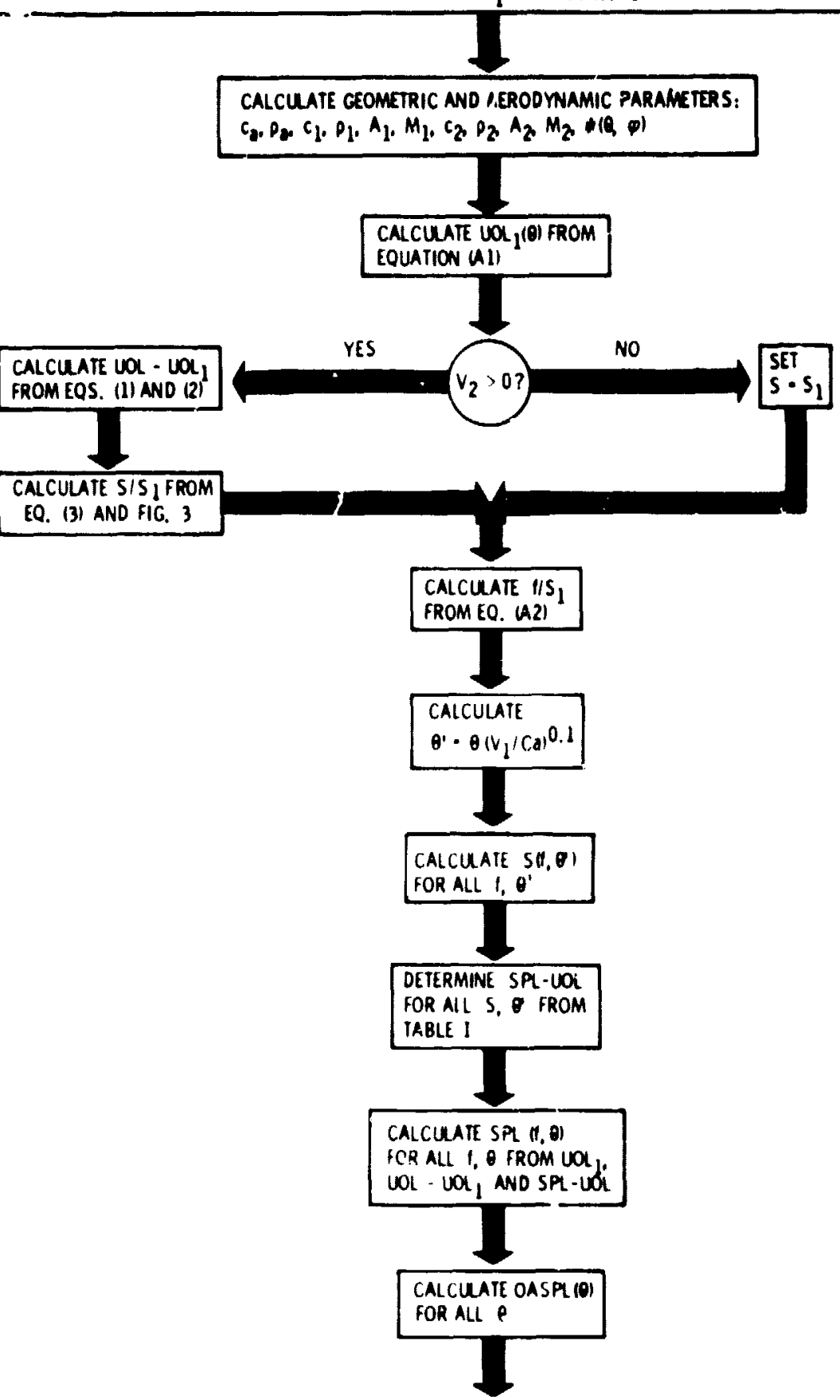

figure 2. Prodiction flow chart. 


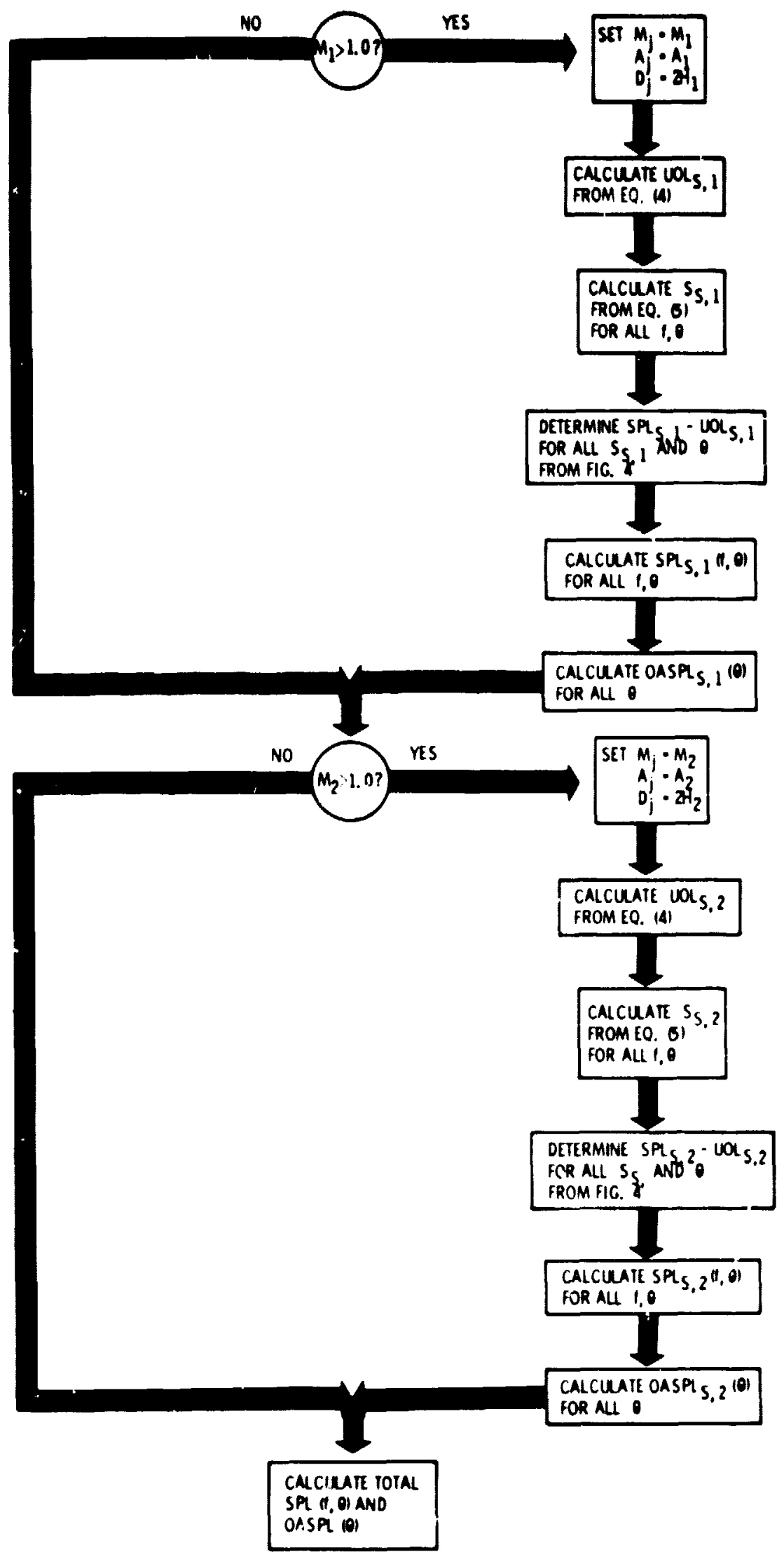

Figure 2 - Concluded 


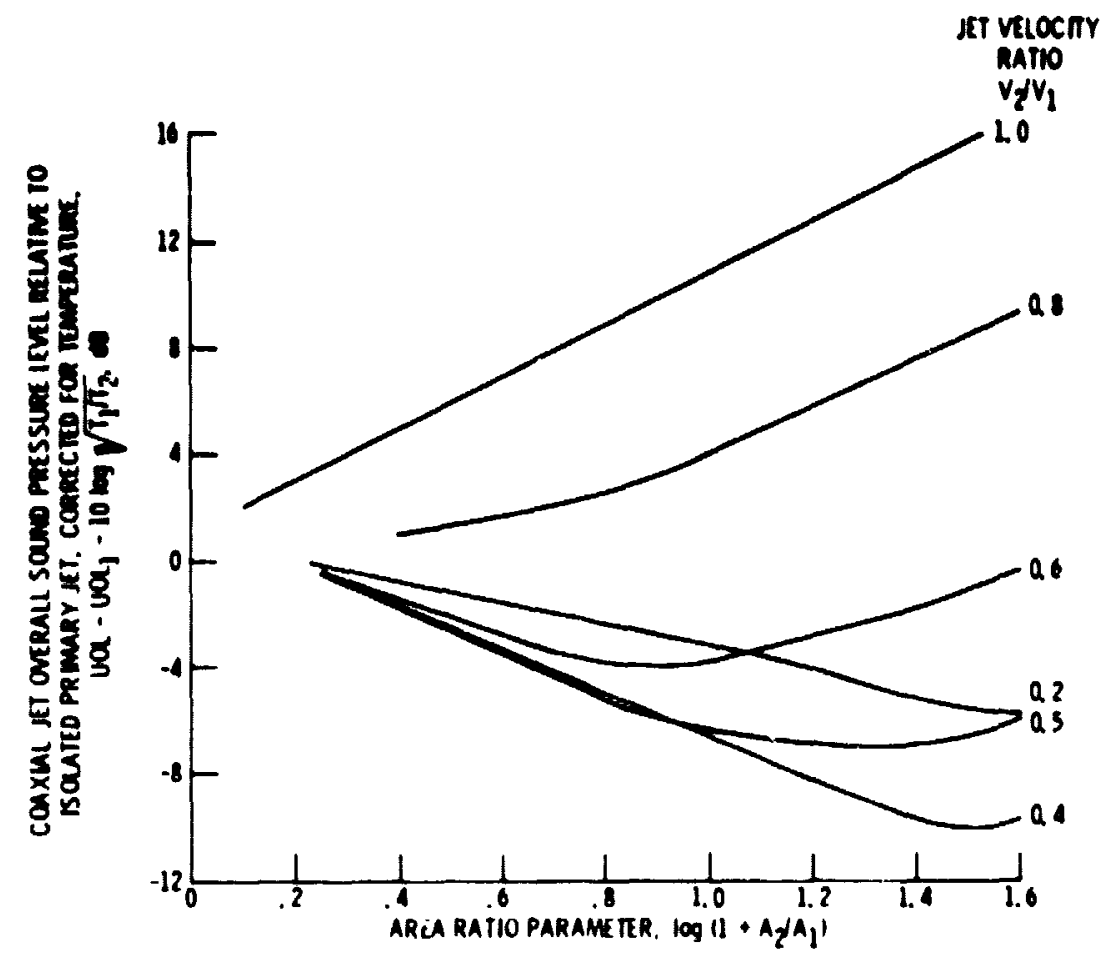

Figure 1. - Recommendad prediction for conxial jet OASPL relotive to isolnted primury jet. besed on extension of the methoo of Osen ind friedmin (ref. 7), cquation (II).

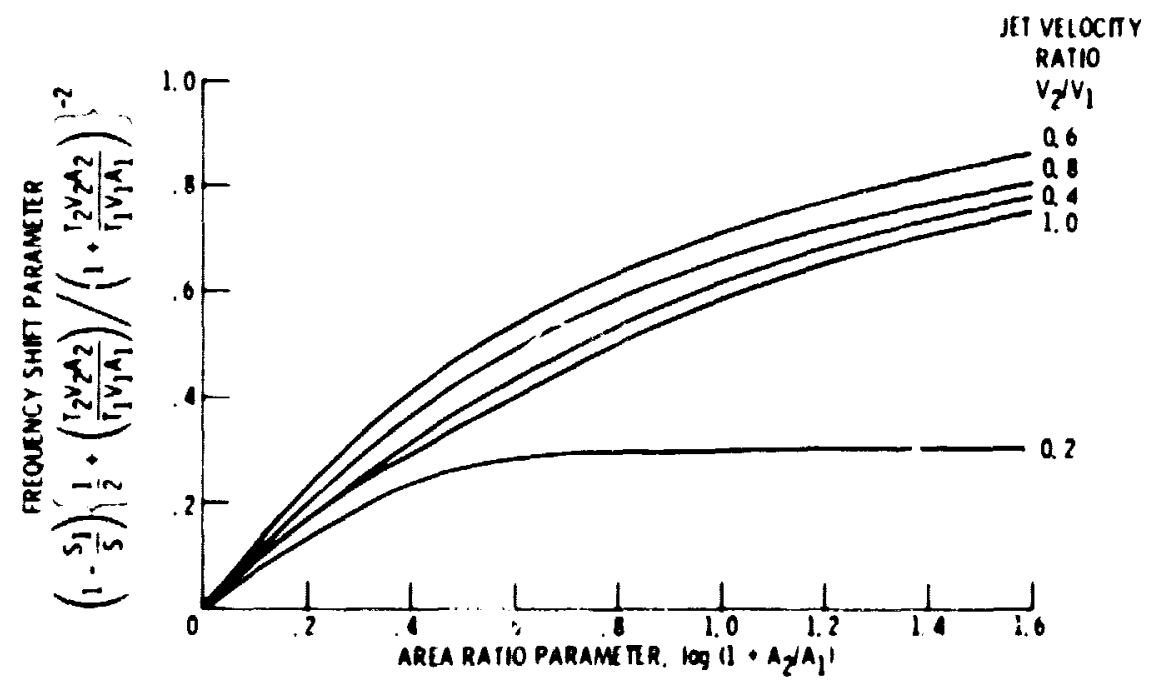

Figure 4. Recommended frequency snift purameder for casibl jets with respact to isoluted primery int. used on extension of the method of asen and fricamen iret. 71 . 


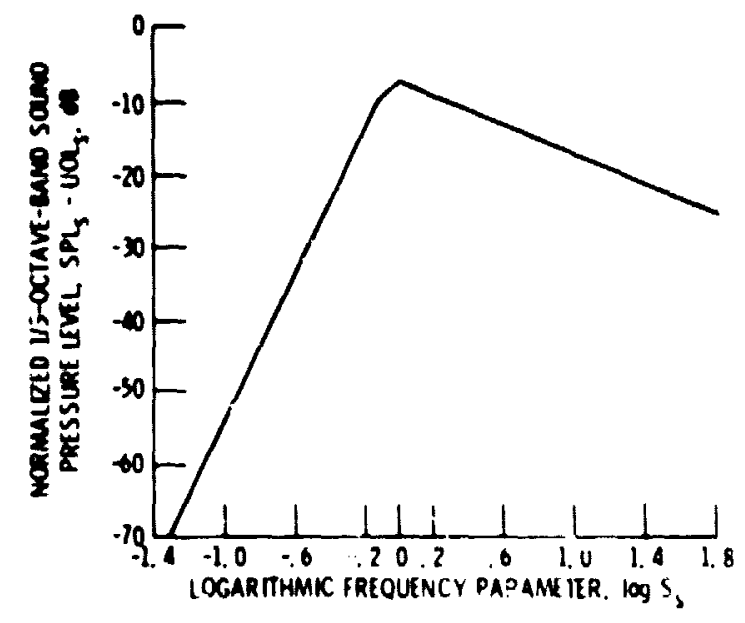

Foures. - Recommended $1 / 3$-octuve and spectrum for shock noise irel. 4 .

\begin{tabular}{ccc} 
PREOICTE & $\begin{array}{c}\text { EXFEI- } \\
\text { MENTAL }\end{array}$ & YIO \\
\hline PAESENT & 0 & 17 \\
\hline & 0 & 0 \\
& 0 & 0 \\
& 0 & 0
\end{tabular}

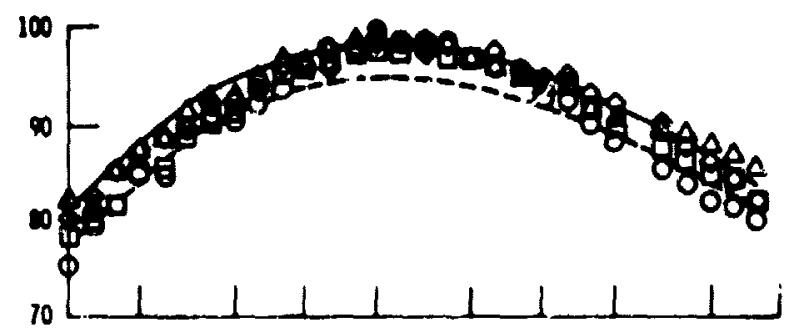

(a) Dir ectivity angle, $\cdot \mathbf{5}^{\circ}$.

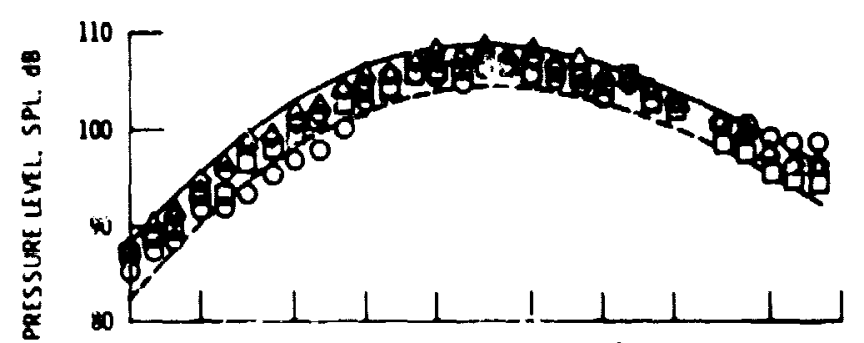

(b) Directivity ongle. $0 \cdot 0^{\circ}$.

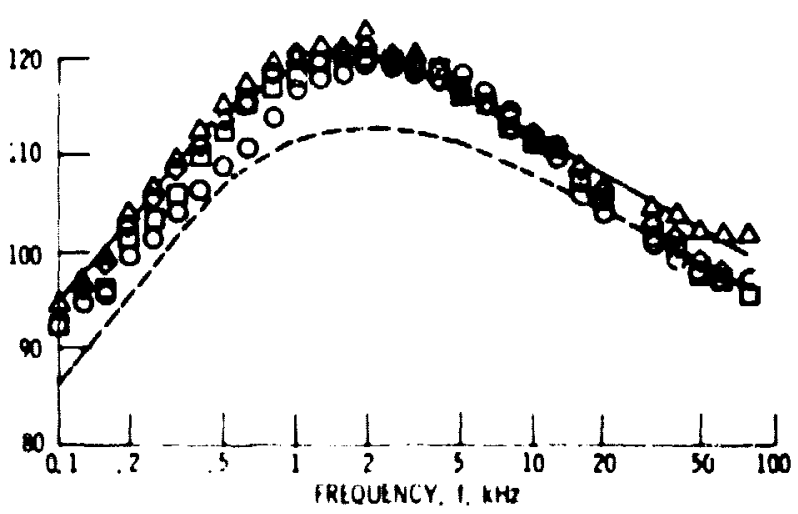

's Dif ectivity angle. $6 \cdot 13^{\circ}$.

figure 0 . Comperison of prediction with lossless tree-fietd experimental subsonic spectro scaled to a $3 \mathrm{C}$-m sideline for 1 . 9- area-

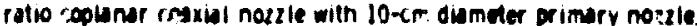
Primery velocity. $V_{1}=500 \mathrm{~m} / \mathrm{sec}$, and temperature $I_{1}-1132 \mathrm{x}$; secondary valocity, $l_{2}-218 \mathrm{misec}$, and temper ature, $\}_{2}-2 \mathrm{ex}$. 


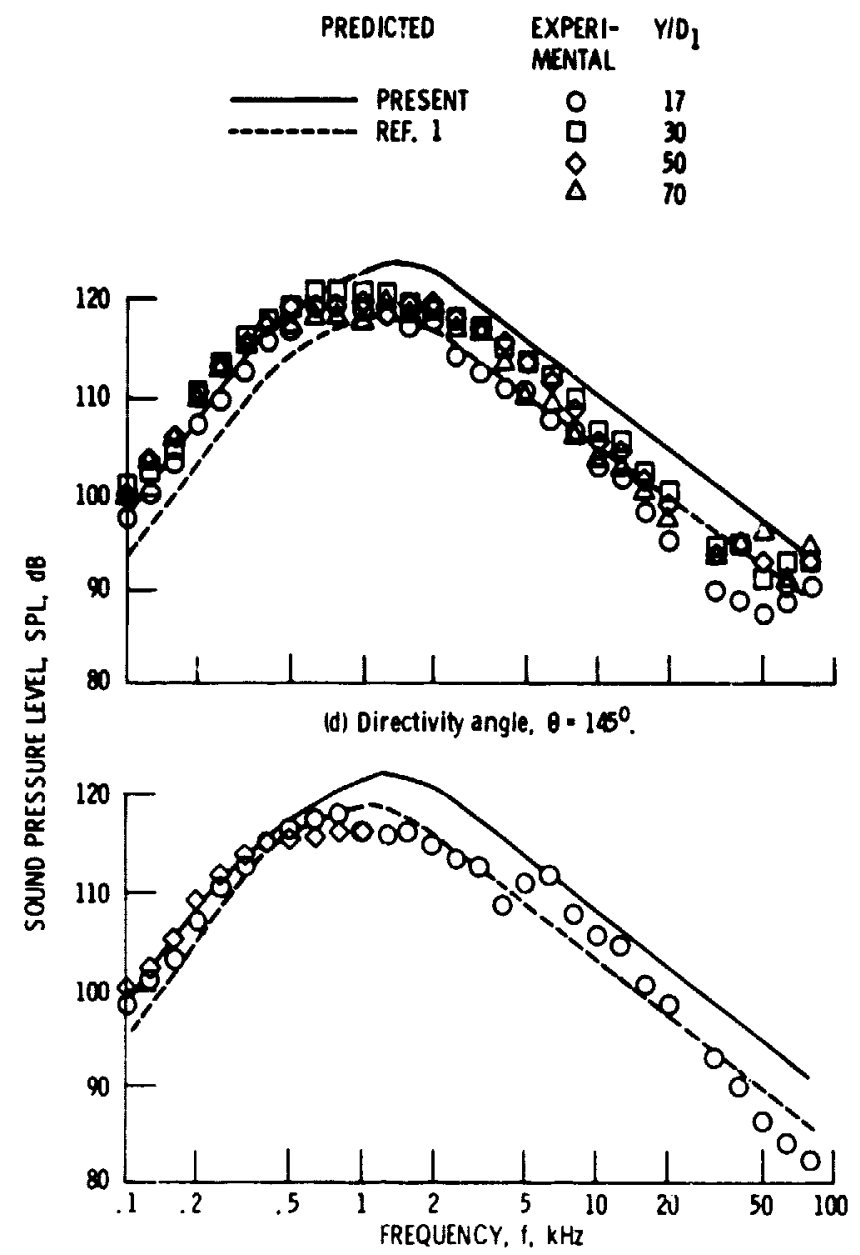

(e) Directivity angle, $\partial-150^{\circ}$.

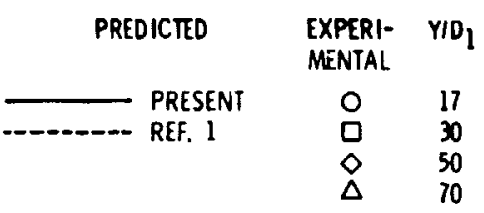

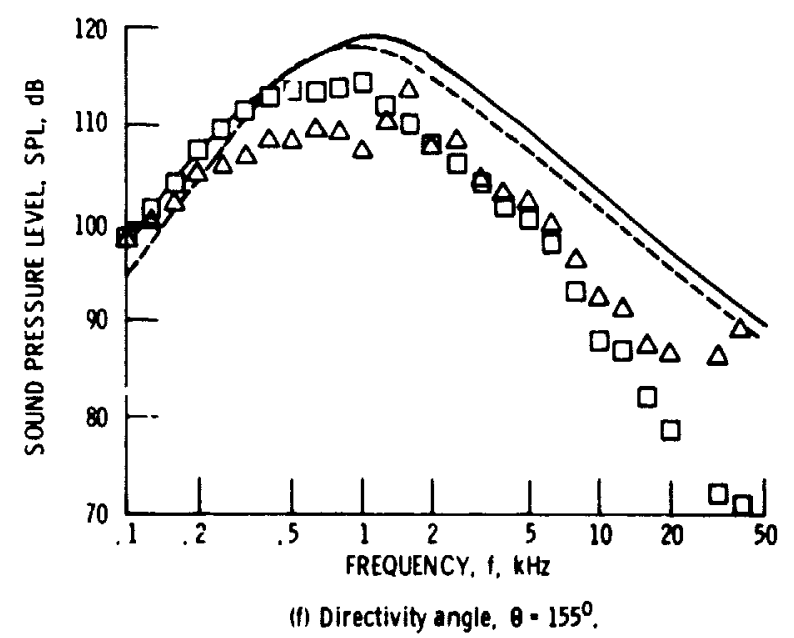

Figure 6. - Concluded. 


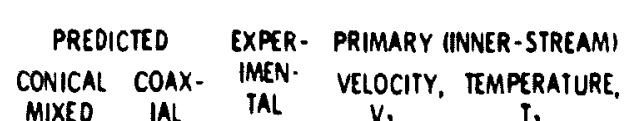

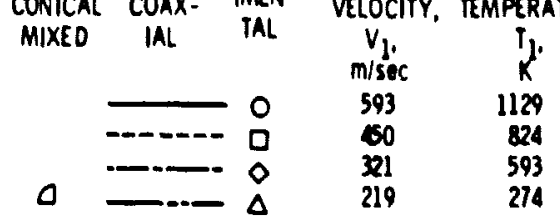

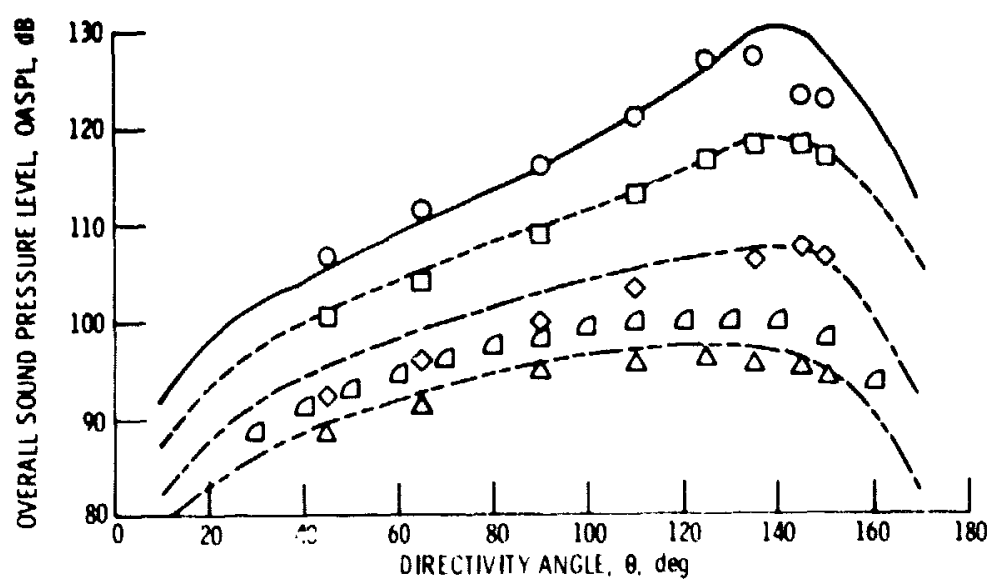

(a) Area ratio. $A_{2} / A_{1}=1.2$; noncoplanar.

Figure 7. - Comparison of predicted and experimental effect of primary conditions on iossiess free-field OASPL directivity on $5.0-\mathrm{m}$ sideline. Secondary velocity. $V_{2}=215 \mathrm{~m} / \mathrm{sec}$, and temperature. $\mathrm{r}_{2}-27 \mathrm{~K}$.

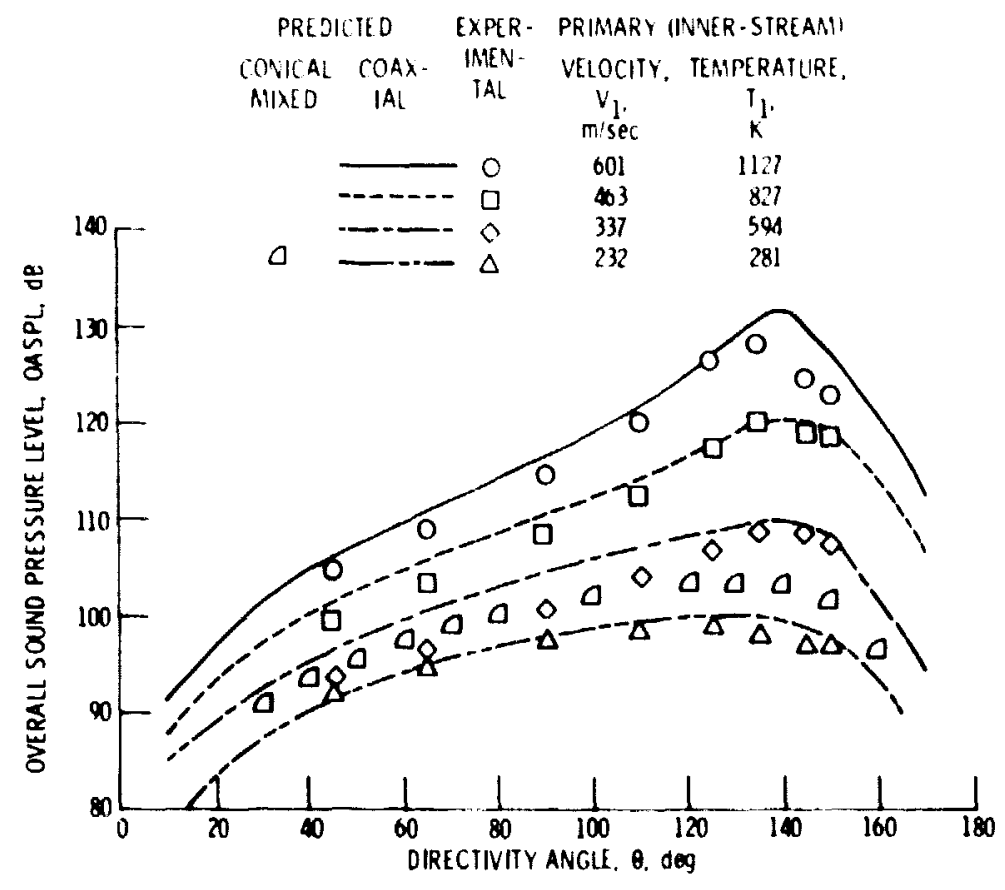

(b) Area ratio. $A_{2} / A_{1} \cdot 1.4$; coplanar.

figure 7. - Continued. 


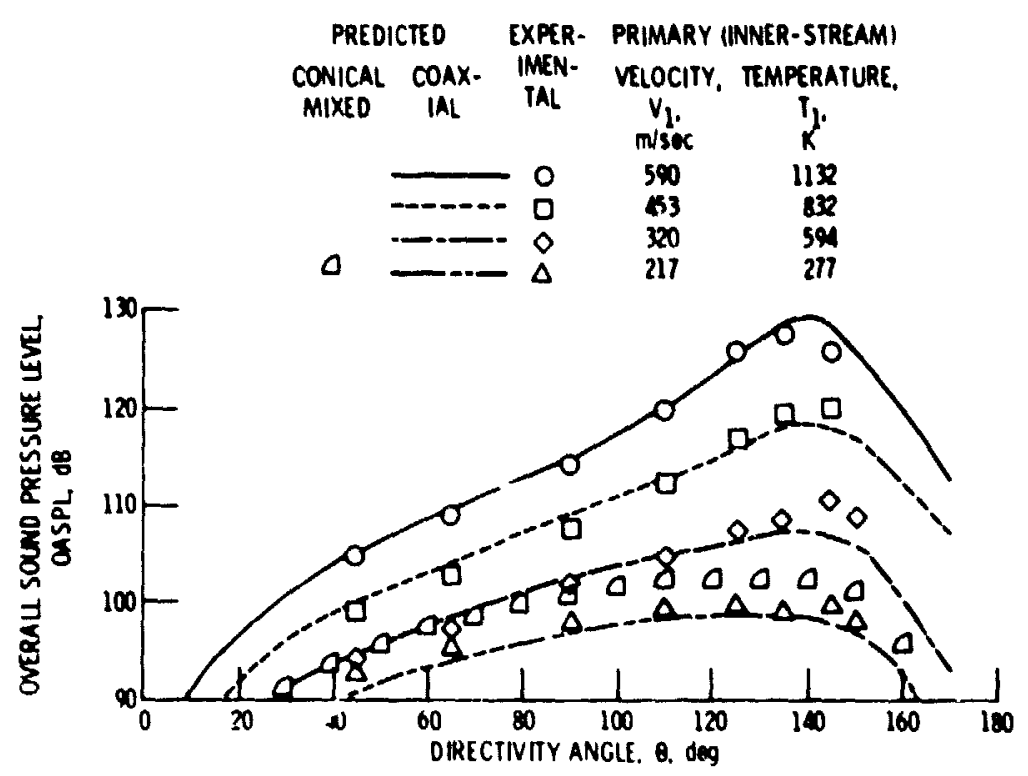

(c) Are ratio. 1.9. coplanar.

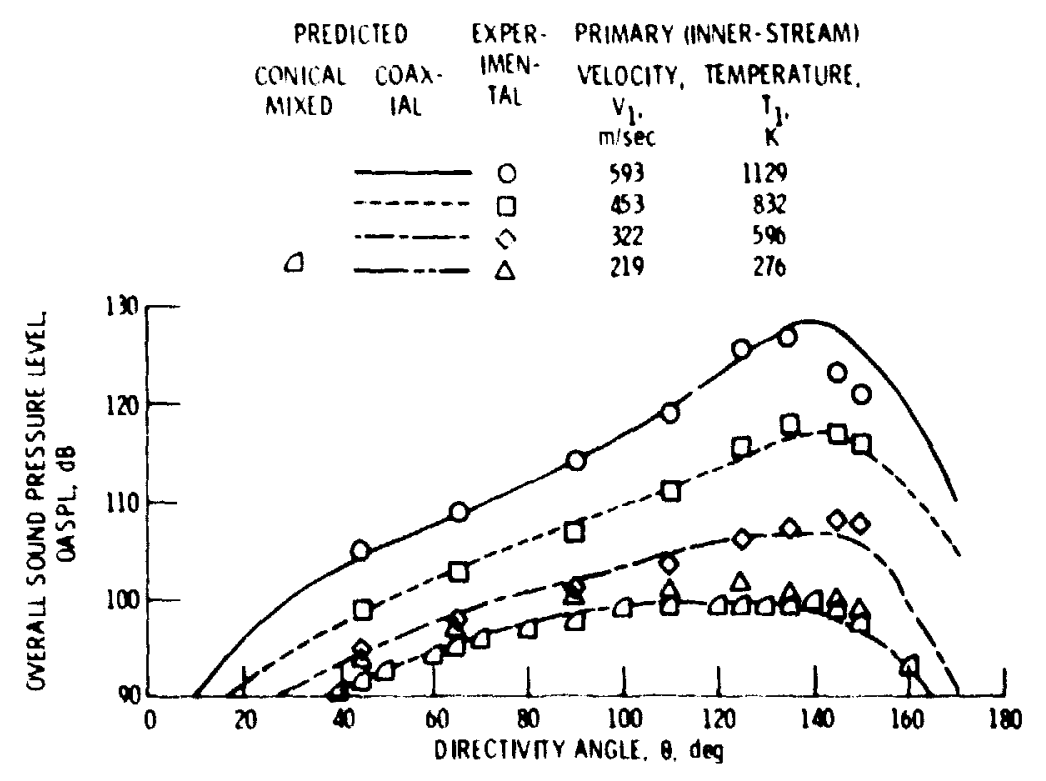

(d) Ares ratio, 3.2, coplenar.

Figure?. - Concluded. 


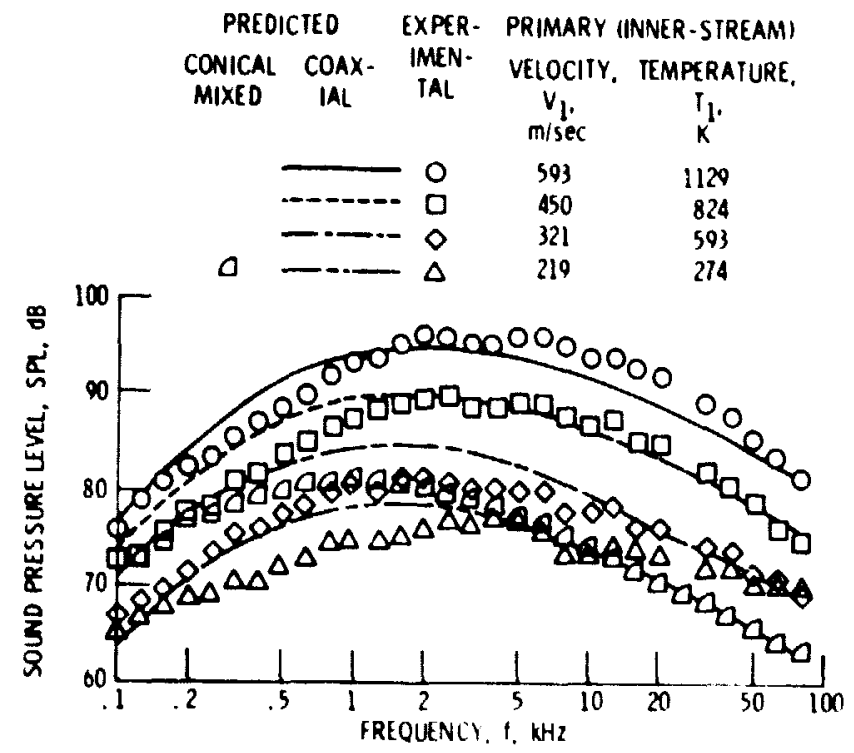

(a) Directivity angle, $\theta \cdot 45^{\circ}$.

Figure 8. - Comparison ol predicted and experimental effect of primary velocity and temperature on lossless Iree-field subsonic spectra at a 5. 0- $\mathrm{m}$ sioeline. 1.2-Ared-ratio coaxial noncoplanar nozzle: primary nozzle diameter, $D_{1} \cdot 10.0 \mathrm{~cm}$; secondary velocity. $v_{2} 215$ $\mathrm{m} / \mathrm{sec}$, and temperature. $\mathrm{I}_{2} \cdot 279 \mathrm{~K}$.
PREDICTED EXPER- PRIMARY INNER-STREAMI CONICAL COAX. IMEN- VELOCITY, TEMPERATURE, MIXED IAL IAL $\begin{gathered}V_{\mathrm{l}} \\ \mathrm{m} / \mathrm{seC}\end{gathered}$

\begin{tabular}{|c|c|c|c|}
\hline & 0 & 593 & 1129 \\
\hline$\cdots$ & 口 & 450 & 824 \\
\hline$-\cdots$ & 0 & 321 & 5 \\
\hline$-\cdots$ & $\Delta$ & 210 & 214 \\
\hline
\end{tabular}

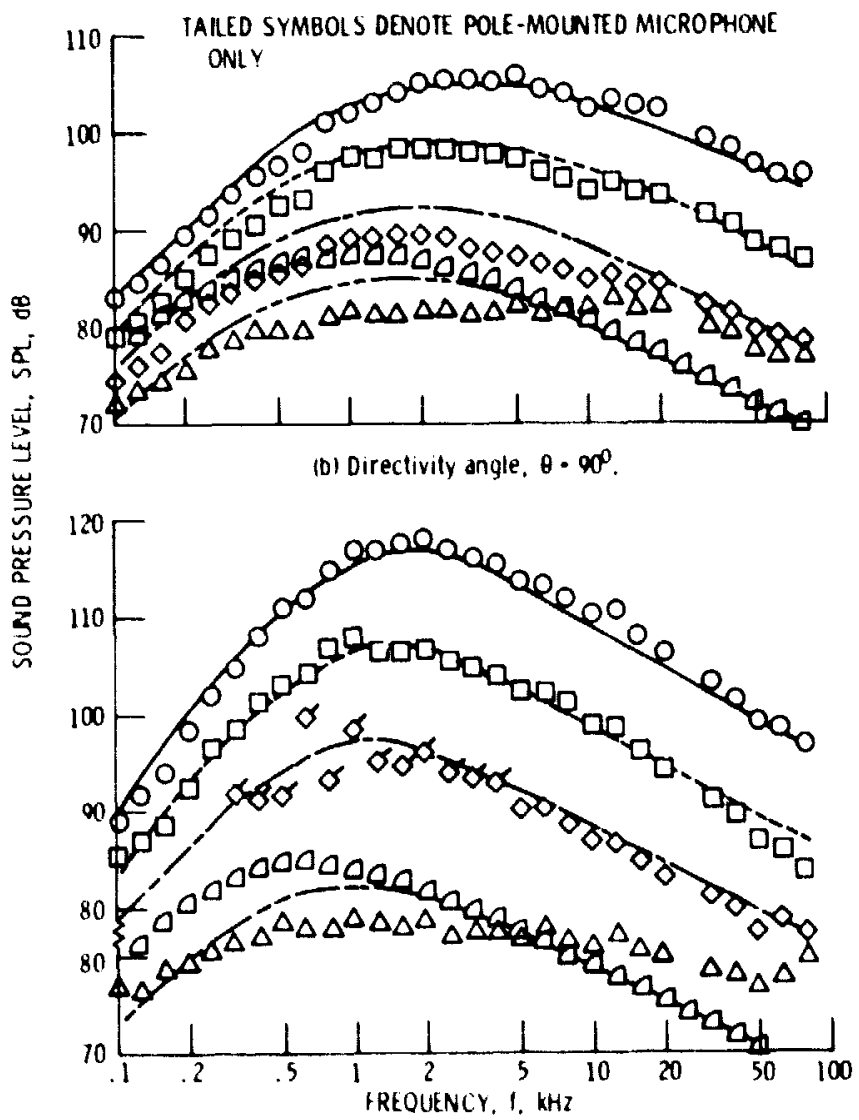

(c) Directivity angle, $\theta \cdot 12^{\circ}$.

figure 8. - continued. 


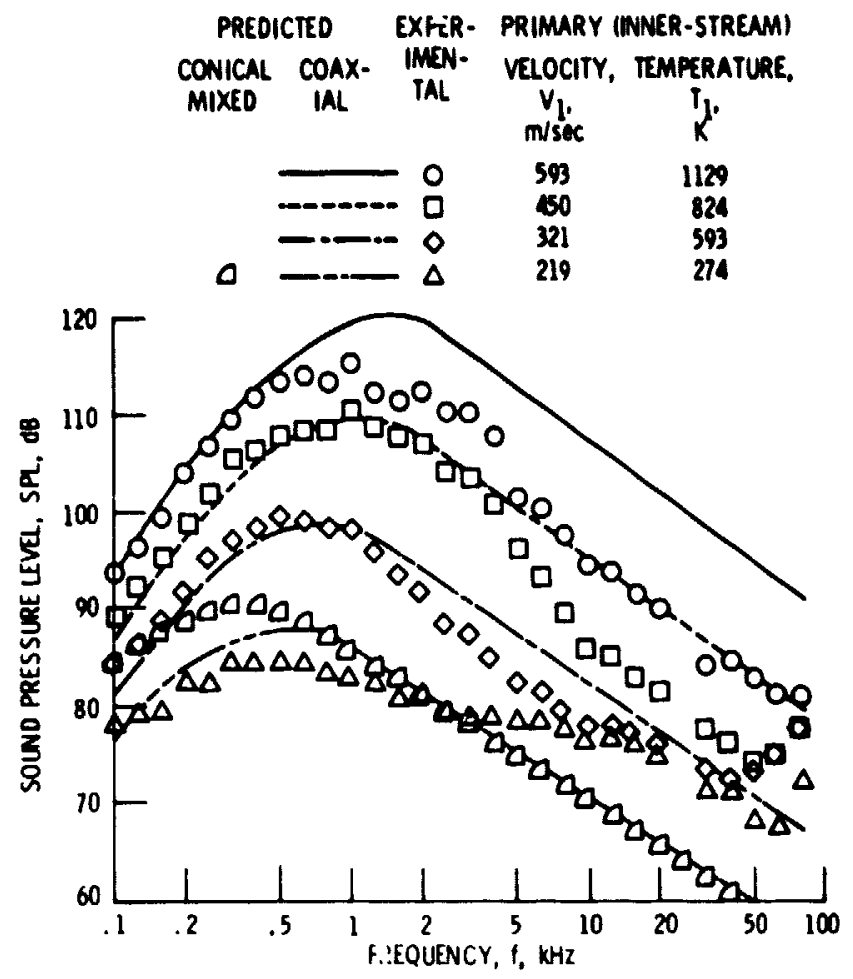

(d) Directivity angle, $\theta \cdot 145^{\circ}$.

Figure 8. - Concluded.

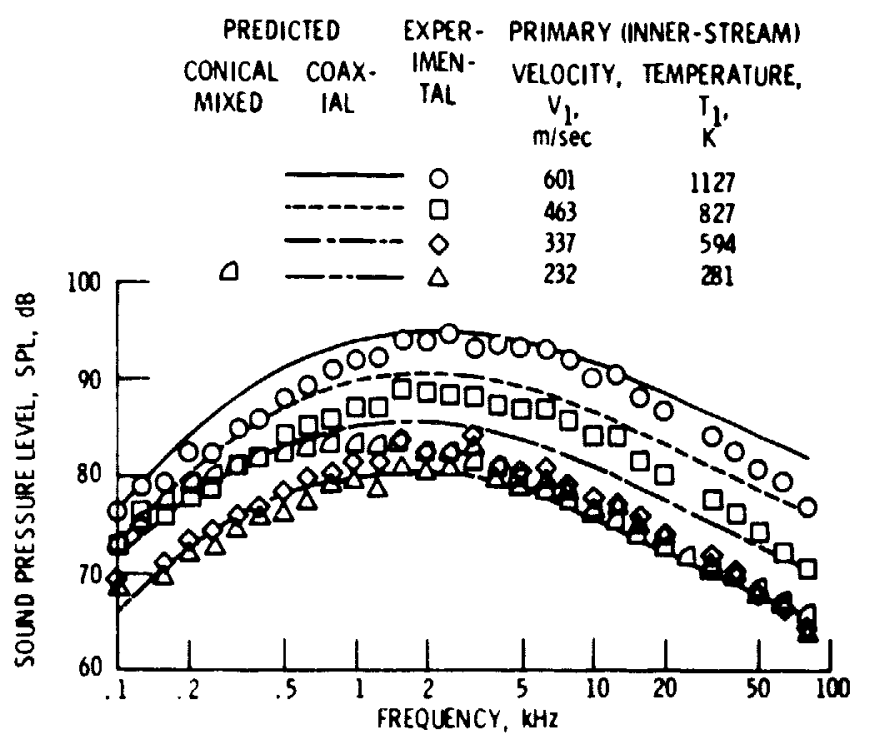

(a) Directivity angle, $\theta=45^{\circ}$.

Figure 9. - Comparison of predicted and experimental effect of primary velocity and temperature on lossless free-field subsonic spectra at 5. O-m sideline. 1.4-Ared-ratio coaxial coplanar nozzle: primary nozzle diameter, $10.0 \mathrm{~cm}$; secondary velocity, $v_{2}=230 \mathrm{~m} / \mathrm{sec}$, and temperature, $t_{2}=286 \mathrm{~K}$. 

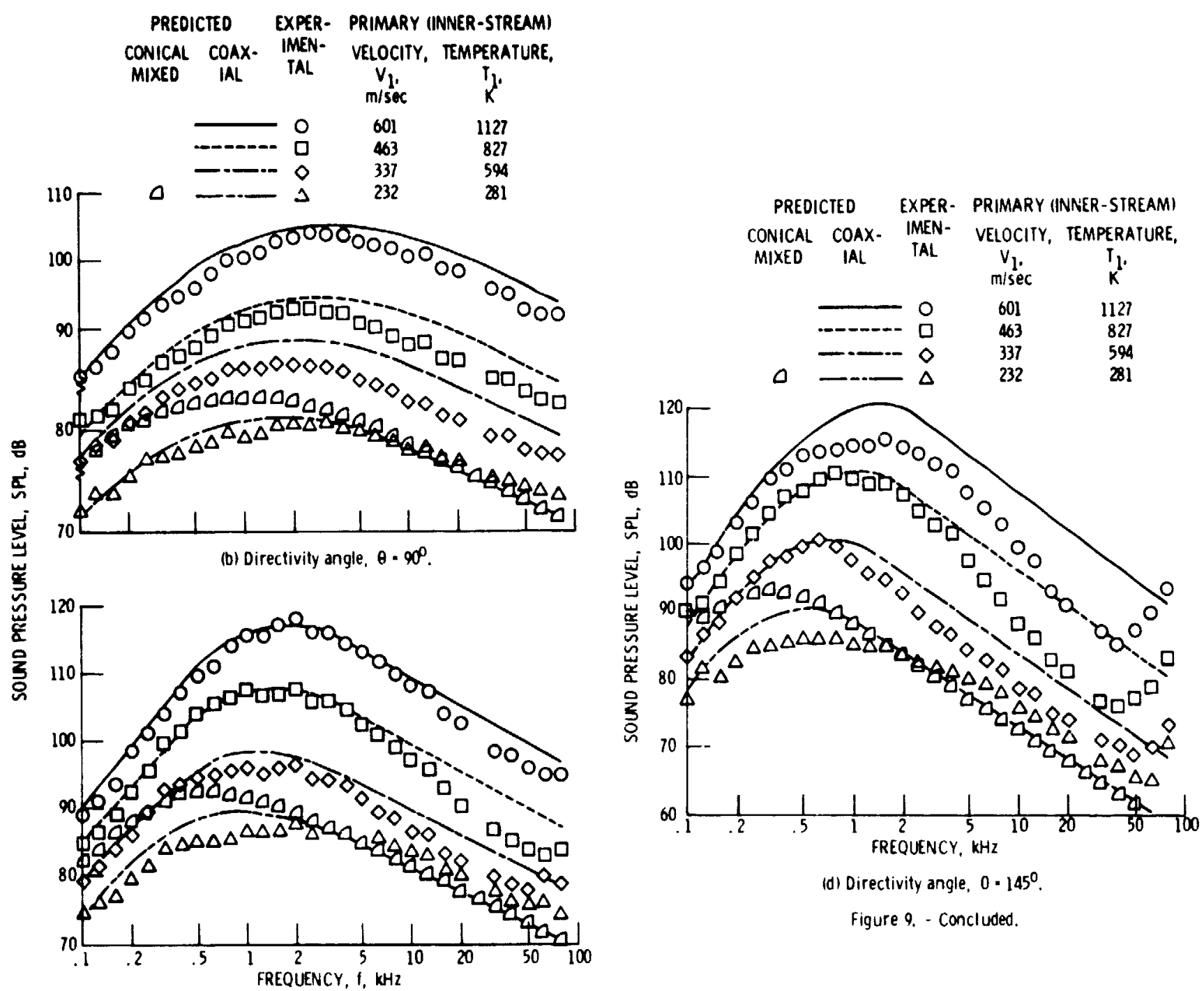

PREDICTED
EXPER- PRIMARY INNER-SIREAMI
CONICAL COAX- IMEN- VELOCITY, TEMPERATURE, MIXED IAL TAL $\begin{gathered}\mathrm{V}_{\mathrm{l}} . \\ \mathrm{m} / \mathrm{sec}\end{gathered} \quad \mathrm{K}$.

$\begin{array}{rrrr} & 0 & 601 & 1127 \\ \cdots \cdots & 0 & 463 & 827 \\ \cdots & 0 & 337 & 594 \\ -\cdots & 0 & 232 & 281\end{array}$

(d) Directivity angle, $0 \cdot 145^{\circ}$.

Figure 9. - concluded.

(c) Directivity angle, $\theta \cdot 125^{\circ}$.

Figure 9 . - Continued. 


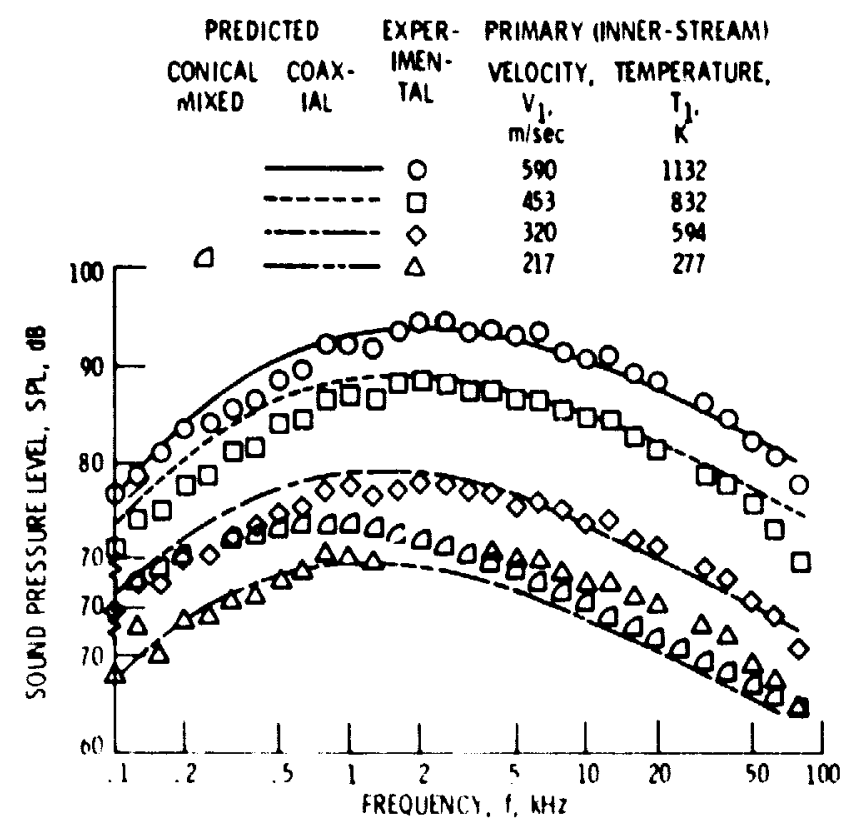

(a) Directivity angle, $9-45^{\circ}$.

Higure 10. Comparison of predicted and experimental effect of primary velocily and temperature on lossless free-field subsonic spectra on $5.0-\mathrm{m}$ sideline. 1.0 fried ratio cosxial coplanar nozzle, primary nozzle diameter, 10. 0-cnz secondary velocity, $v_{2}-217 \mathrm{~m} / \mathrm{sec}$, and temperature, $\mathrm{I}_{2}-277 \mathrm{~K}$

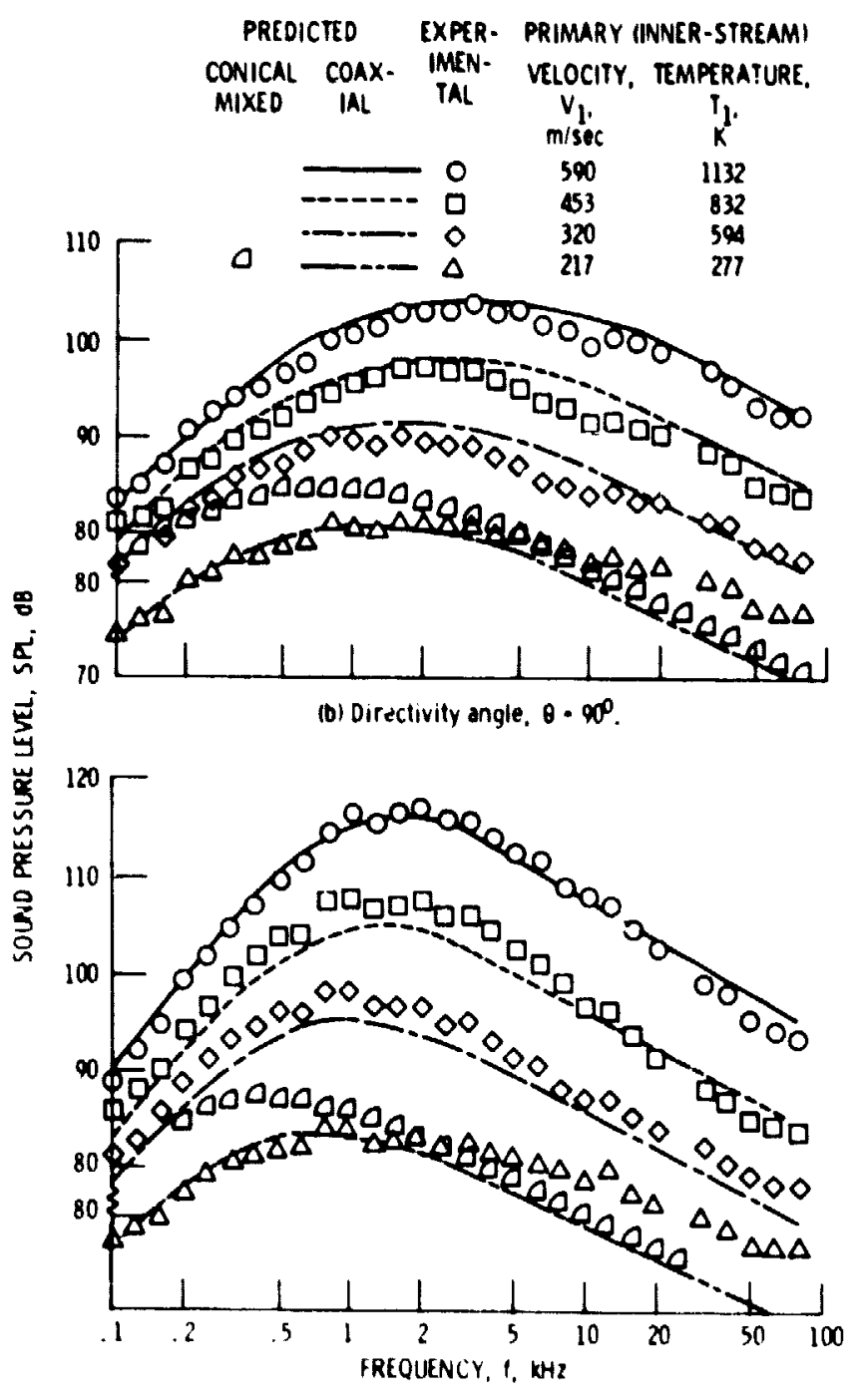

(c) Directivity angle, $\theta \cdot 15^{\circ}$.

figure 10. Continued. 


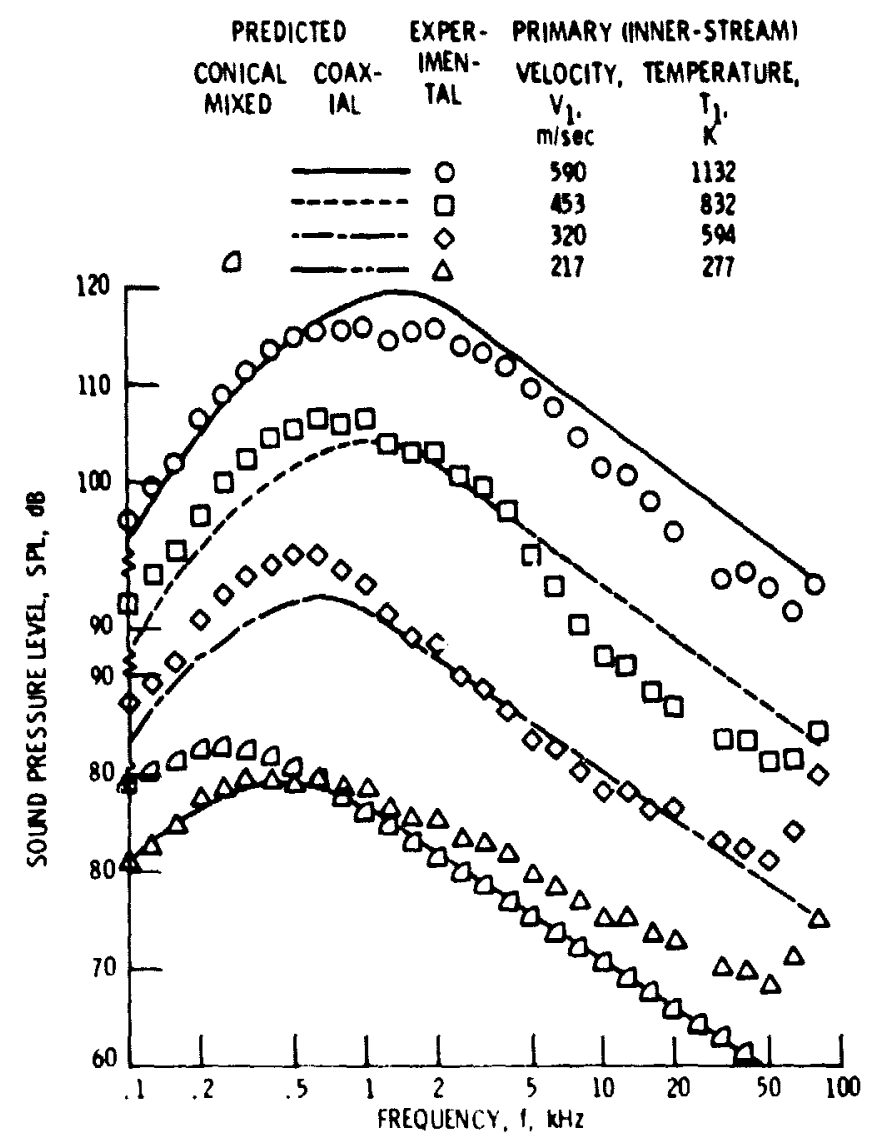

(d) Directivity angle, $\theta \cdot 145^{\circ}$.

Figure 10. Concluded.

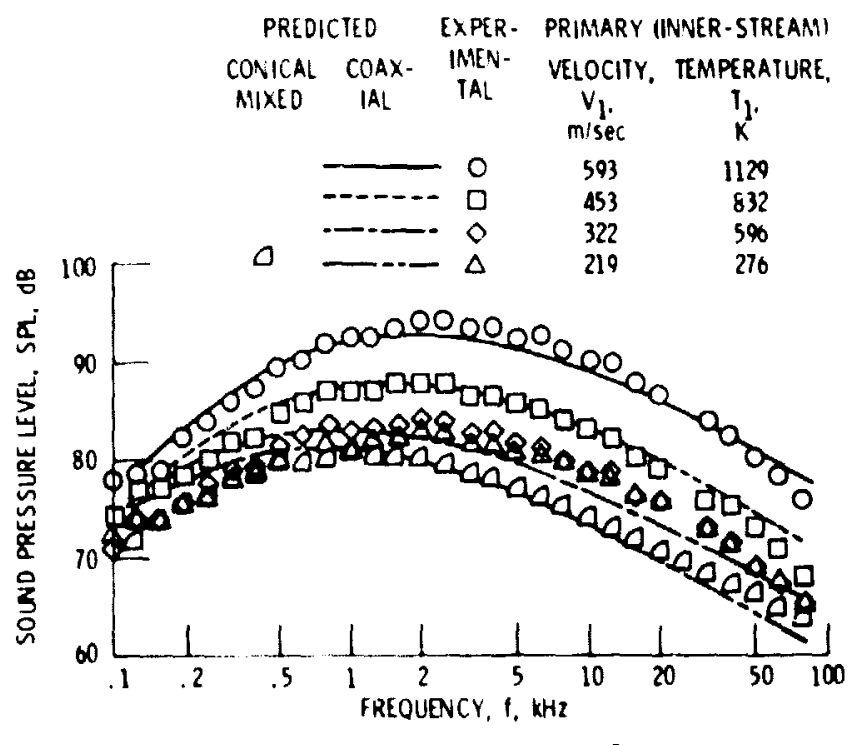

(a) Directivity engle, $\theta \cdot 45^{\circ}$

Figure 11. - Comparison nt nrest ted and experimenta: effect of primary velocity and temper ature on lossless free-field subsonic spectra at 5.0-m sideline. 3.2-Area-ratio coasial coplanar nozzle, primary nozzle diameter, $10 \mathrm{~cm}$ secondary velocity $V_{2} \quad 216 \mathrm{~m} / \mathrm{sec}$, and temperature, $i_{2}-280 \mathrm{~K}$. 

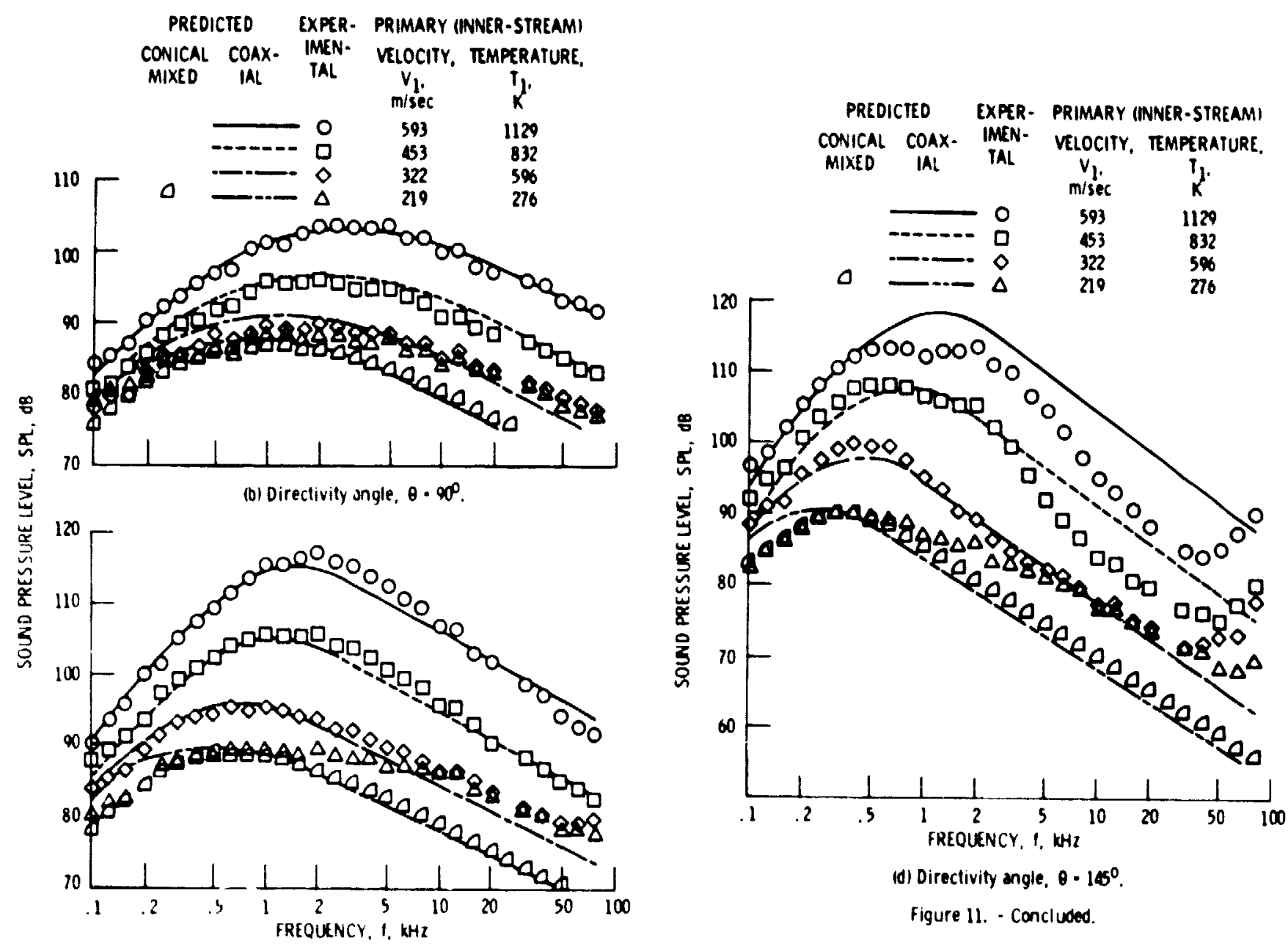

(d) Directivity angle, $\theta-145^{\circ}$.

figure 11. - Concluded.

(c) Directivity angle, $\theta \cdot 12^{\circ}$.

Figure 11. - Continued. 


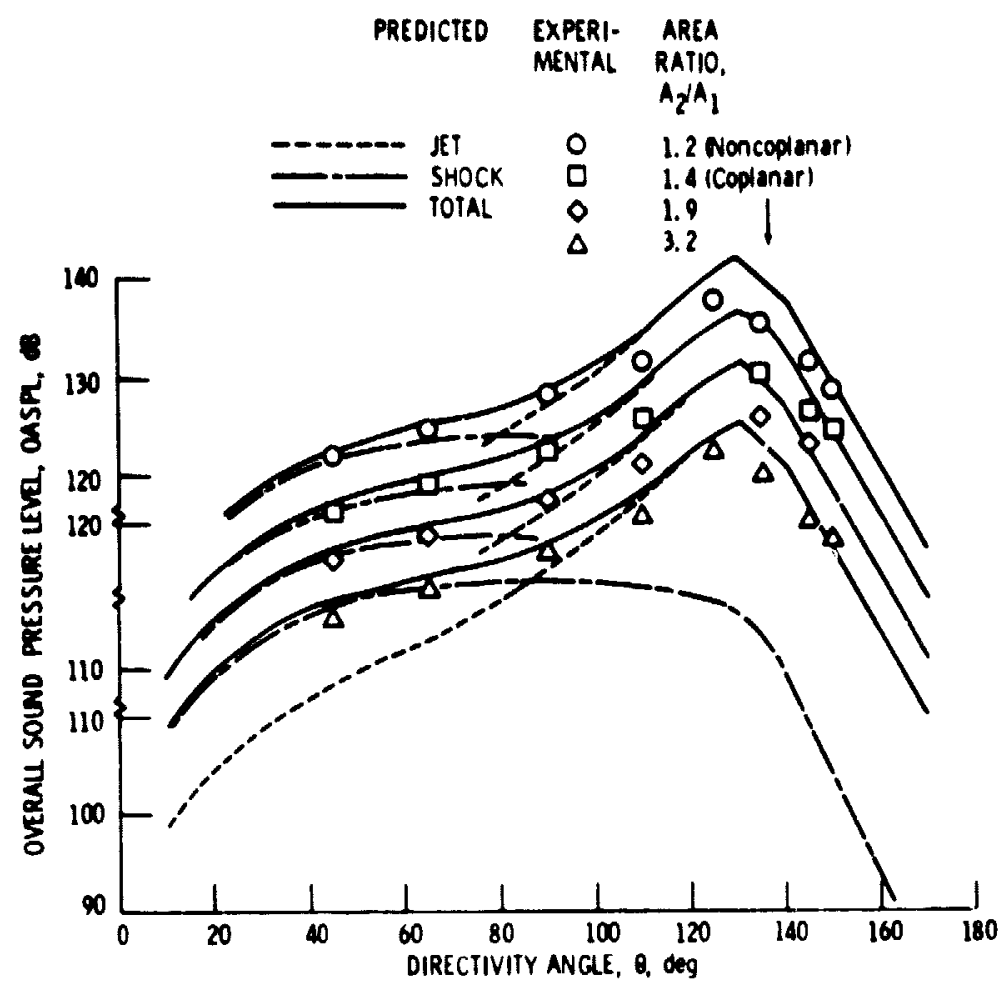

(a) High primary Mach no., $M_{1}-1.3$, high primary velocity.

$v_{1}=790 \mathrm{~m} / \mathrm{sec} \mathrm{T}_{1} \approx 1130 \mathrm{Kt}$.

Figure 12. - Comparison of predicted and experimental effect of area ratio on supersonic jet mixing and shock noise lossless free-field OASPL directivity on $5.0-\mathrm{m}$ sideline. Primary nozzle diameler, $10,0 \mathrm{~cm}$ subsonic secondary velocity, $v_{2}=216 \mathrm{~m} / \mathrm{sec}$, and temperature, $I_{2} \simeq 278 \mathrm{~K}$ loala of ref. 11 .

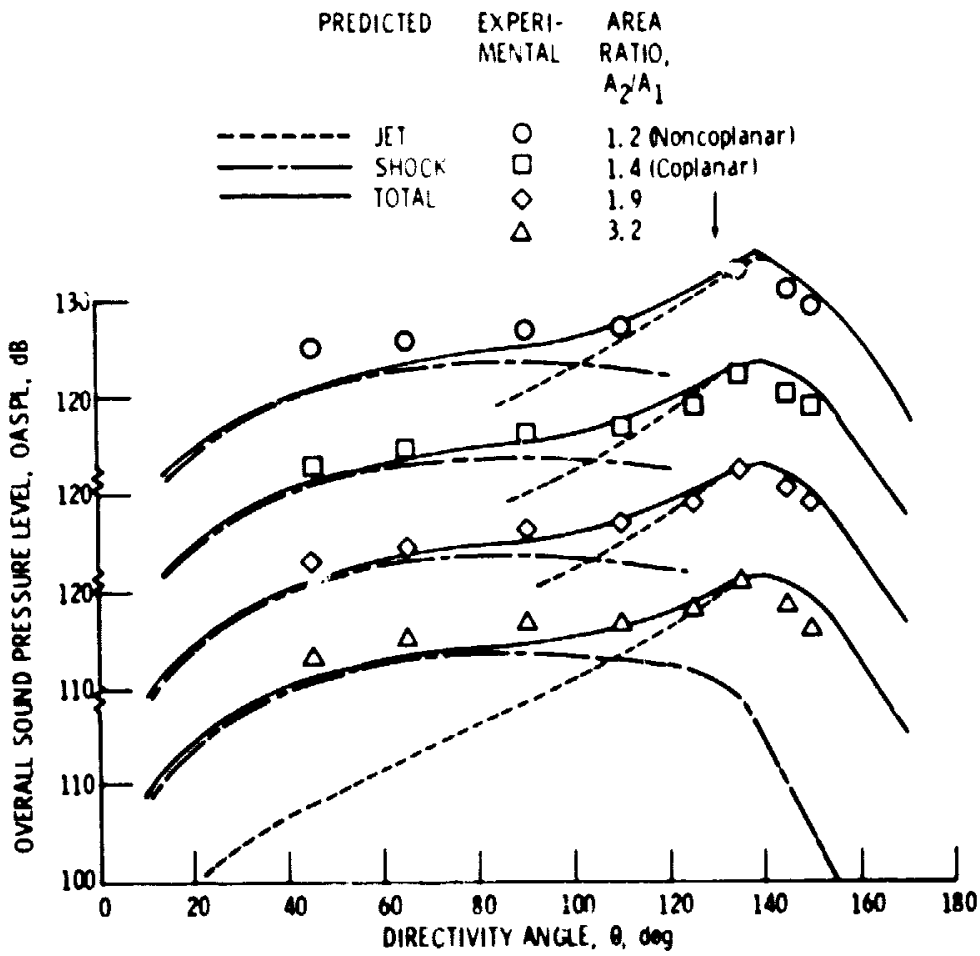

(b) High primary Mach no., $M_{1}-1.2$ moderate primary velocity.

$\left.v_{1}=570 \mathrm{~m} / \mathrm{sec} \pi_{1} \cdot 600 \mathrm{~K}\right)$.

Figure 12. - Continued. 


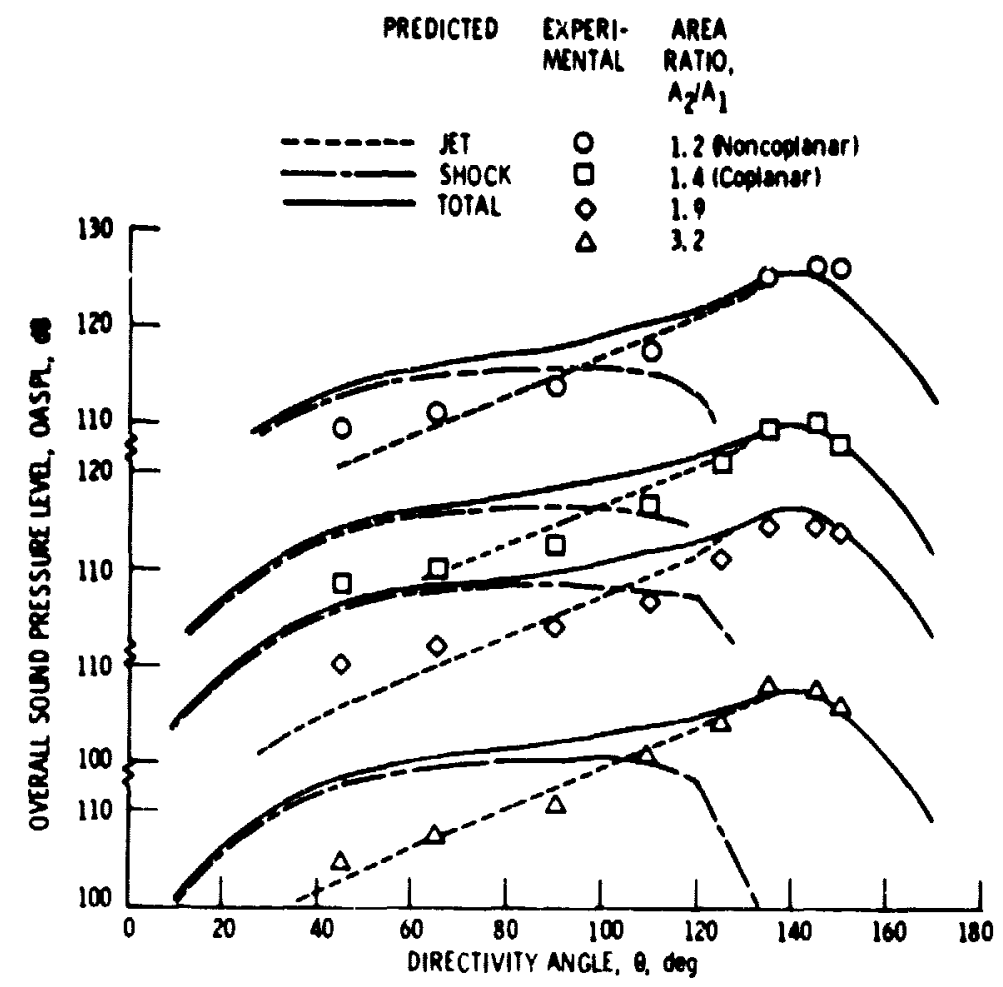

ic) Low primary Mach no., $M_{1}: 1.12$ low primary velocity.

$V_{1}=400 \mathrm{~m} / \mathrm{sec} \pi_{1}=500 \mathrm{~K}$.

Figure 12. Concluded.
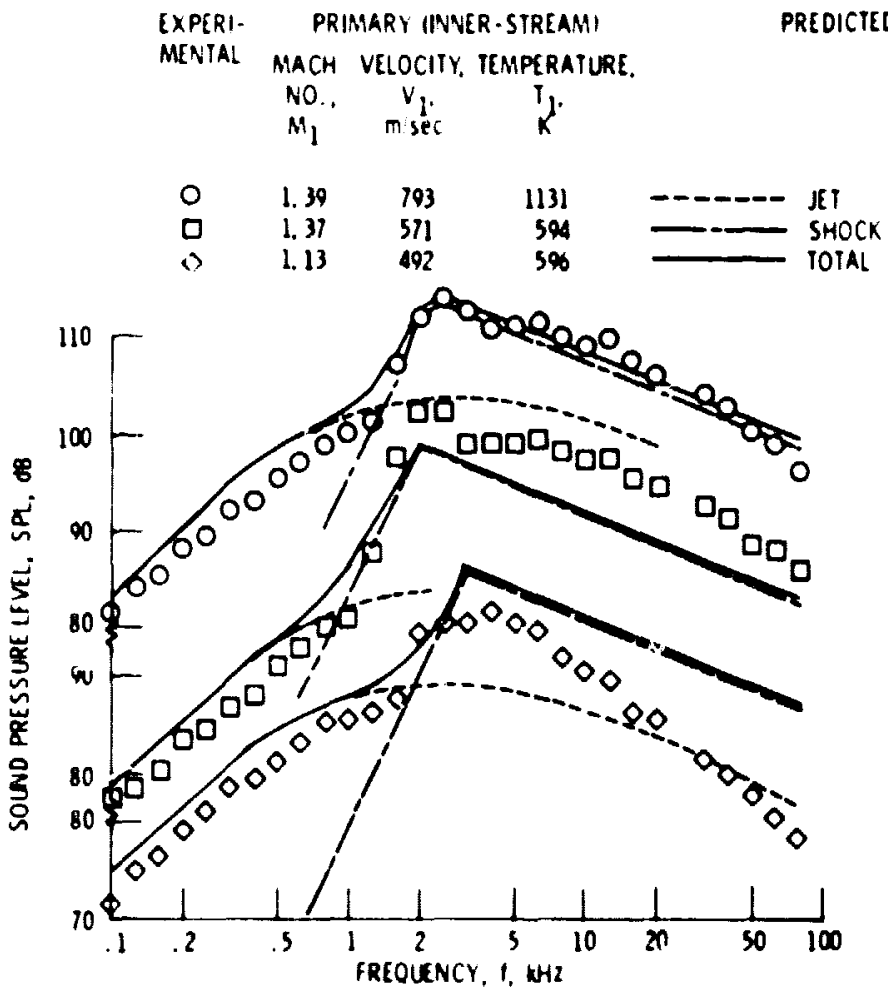

(a) Directivity angle, $0-45^{\circ}$.

ligure 15. Comparison of predictod and experimental effect of supersonic primary conditions on lossless free-field spectr: a $5.0-\mathrm{m}$ sioeline. 1.2-Area-ratio noncoplenas casial nozzle. primary diameter $10 \mathrm{~cm}$ secondary velocity, $v_{2} 215 \mathrm{~m} / \mathrm{sec}$, and temperature. $\mathrm{I}_{2} \cdot 370 \mathrm{~K}$. 


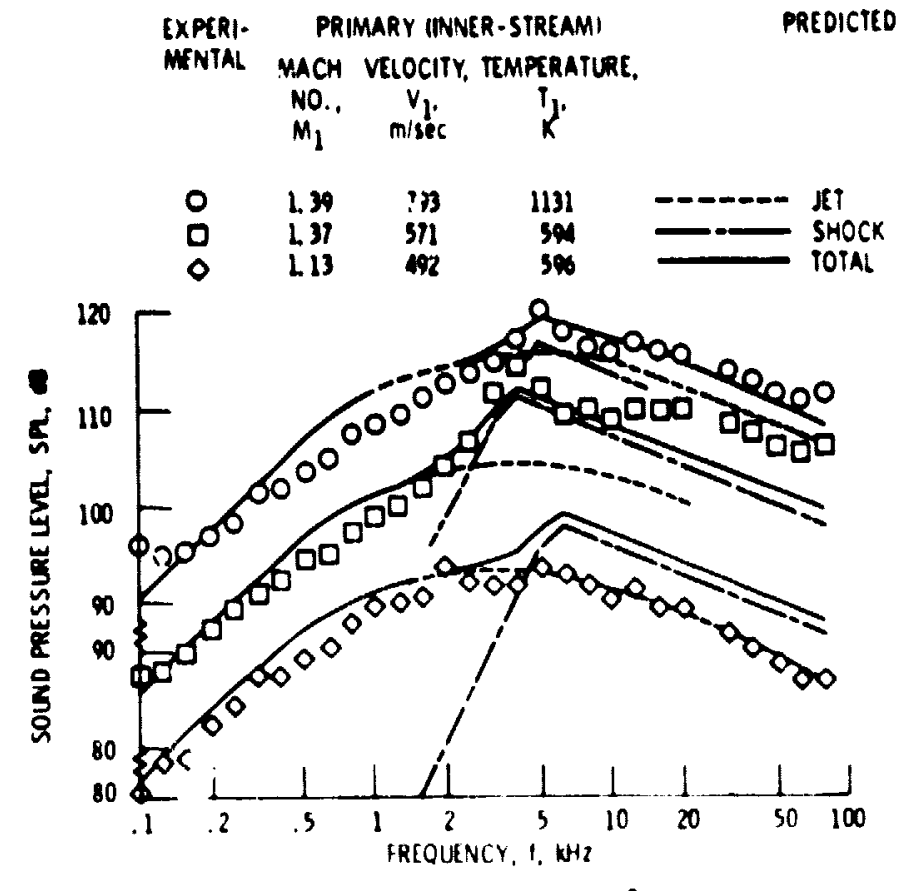

(b) Directivity angle, $\theta-90^{\circ}$.

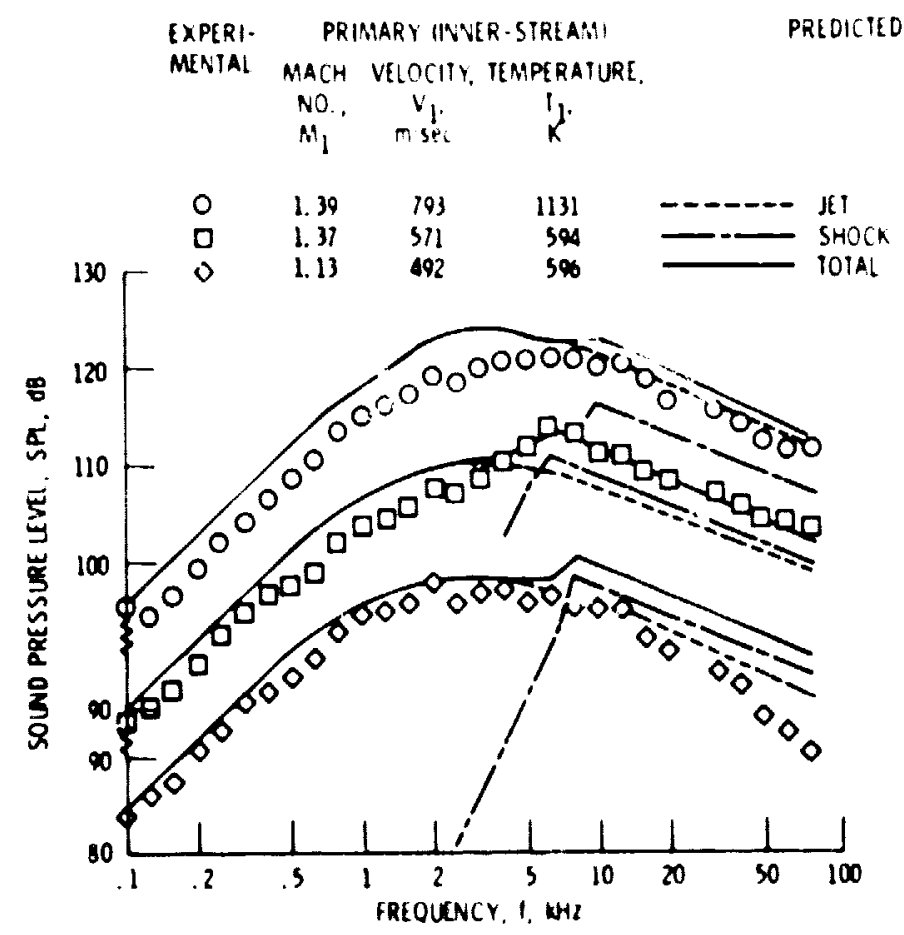

(C) Direclivily angle, $0 \cdot 110^{\circ}$.

figure 13, - continued. 


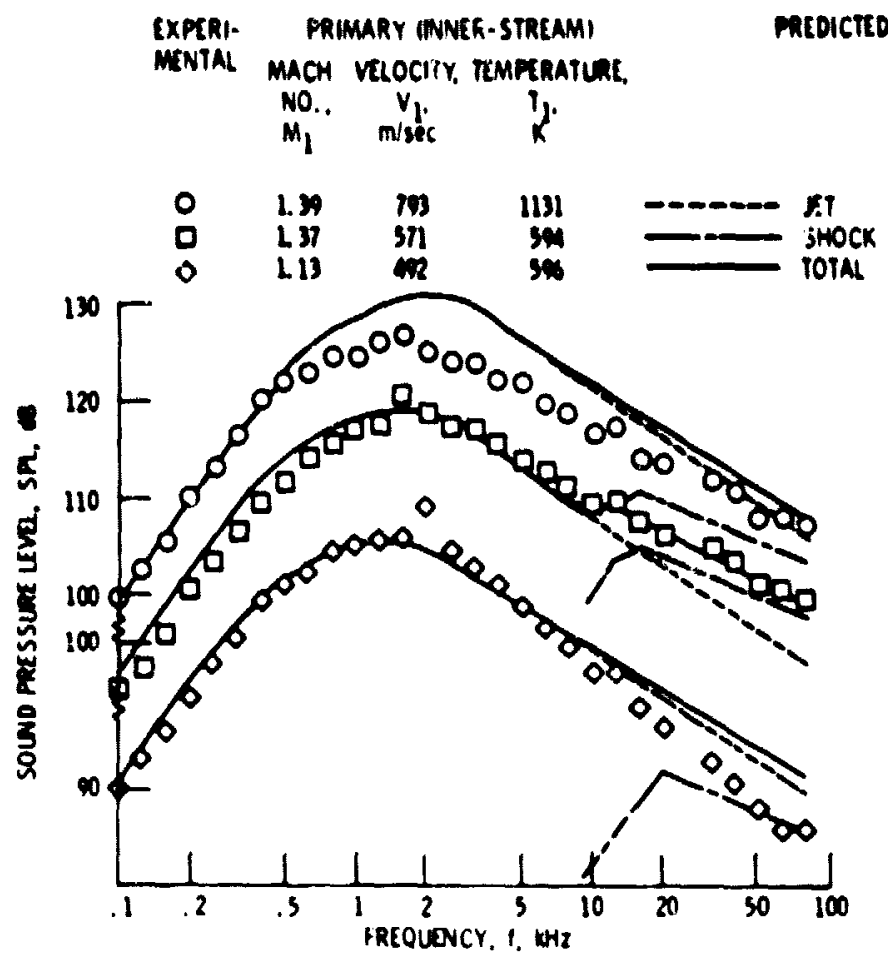

(d) Directivity engle, $0 \cdot 13^{\circ}$.

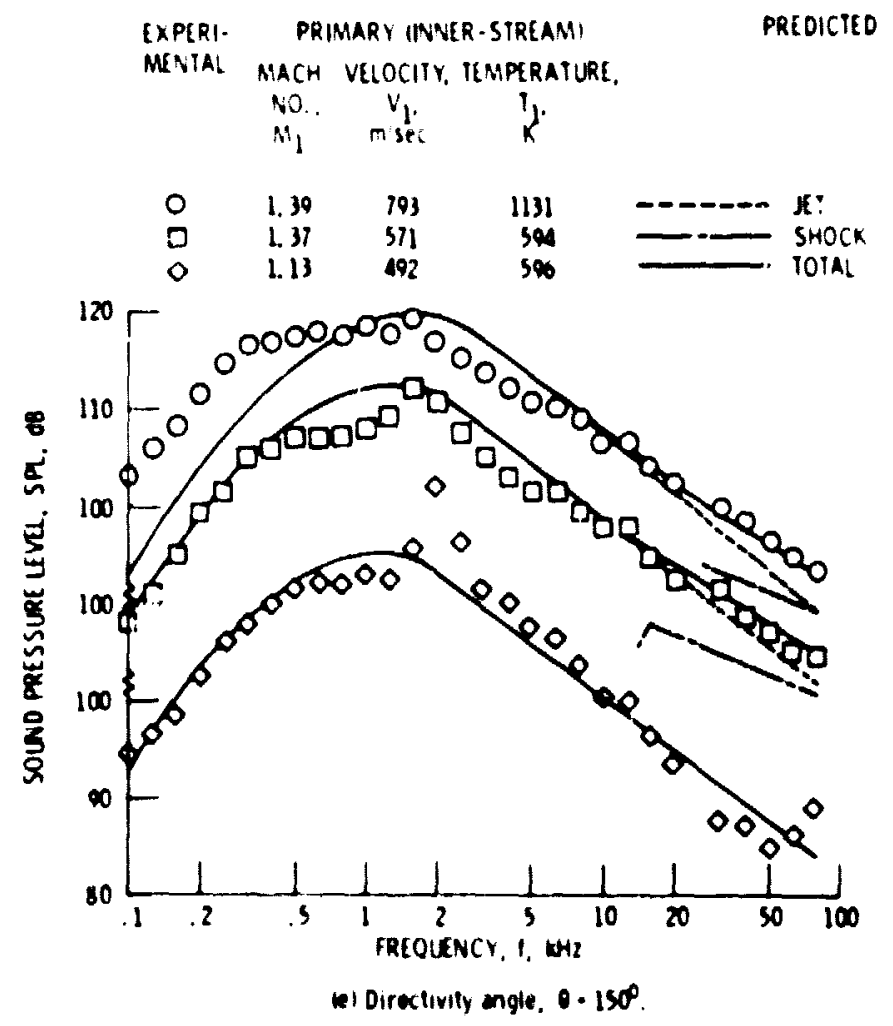

figure 13. - Concluad. 

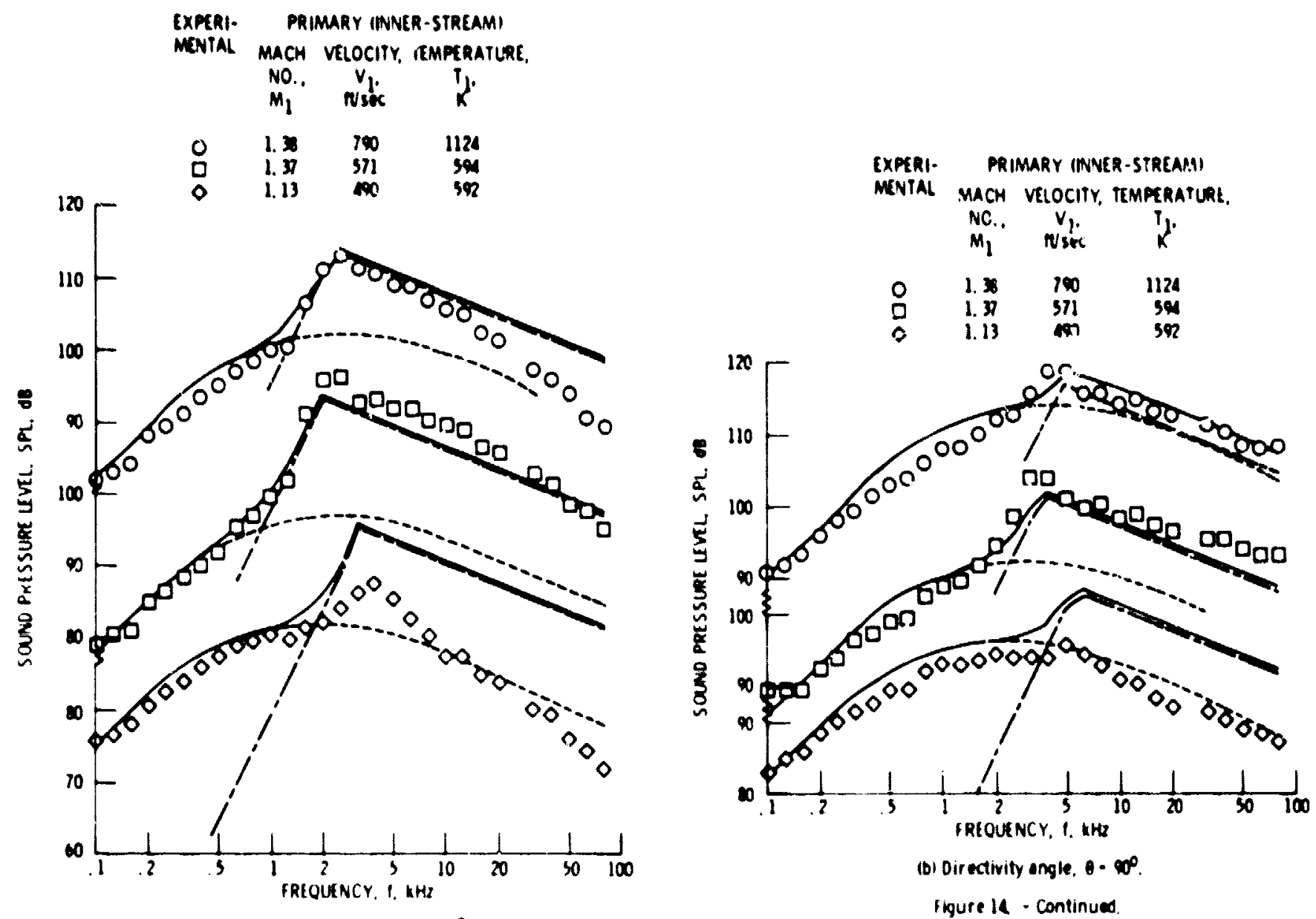

w) Direstivity angle. $0 \cdot \mathbf{5}^{\circ}$.

(b) Dir ectivity angle, $\theta-\infty 0^{\circ}$.

Iigure 14 - continued.

figure 14 - Comparison of prodicted and experimental eftect of super-

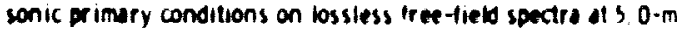

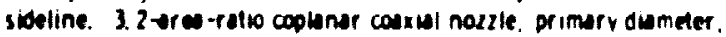
$10-\mathrm{cm}$; secondary velocity, $v_{2} 210 \mathrm{~m} / \mathrm{sec}$ and temperefure. $\mathrm{I}_{2}=\operatorname{2max}$. 


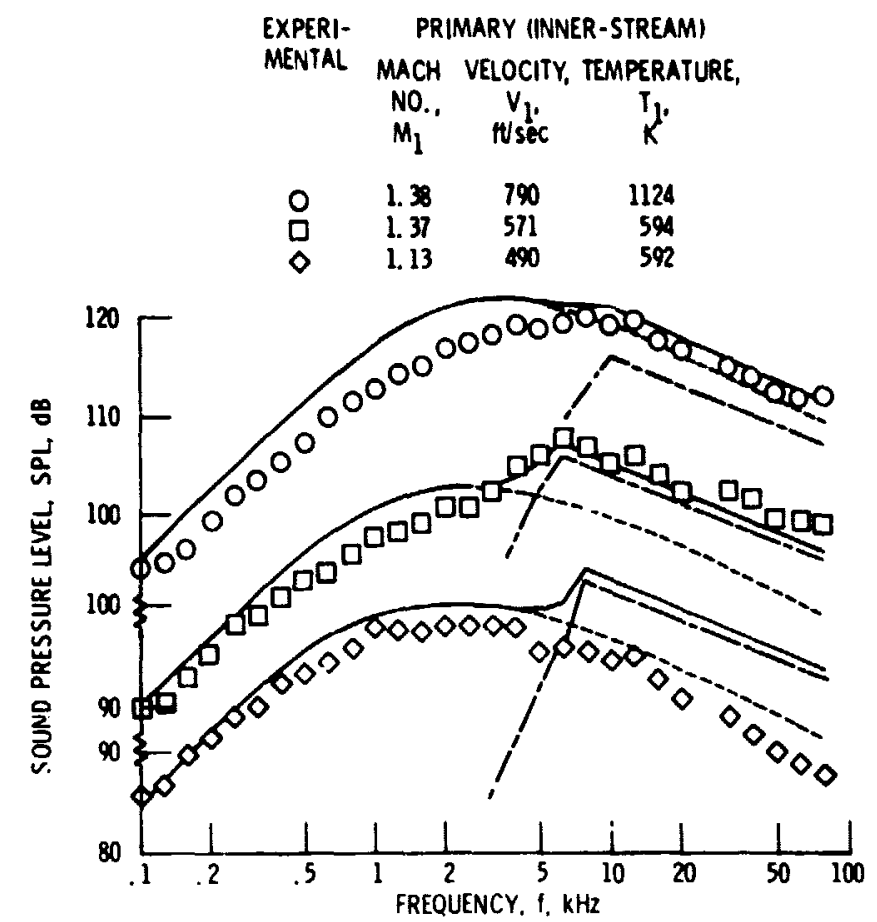

(c) Directivity angle, $\theta=110^{\circ}$.

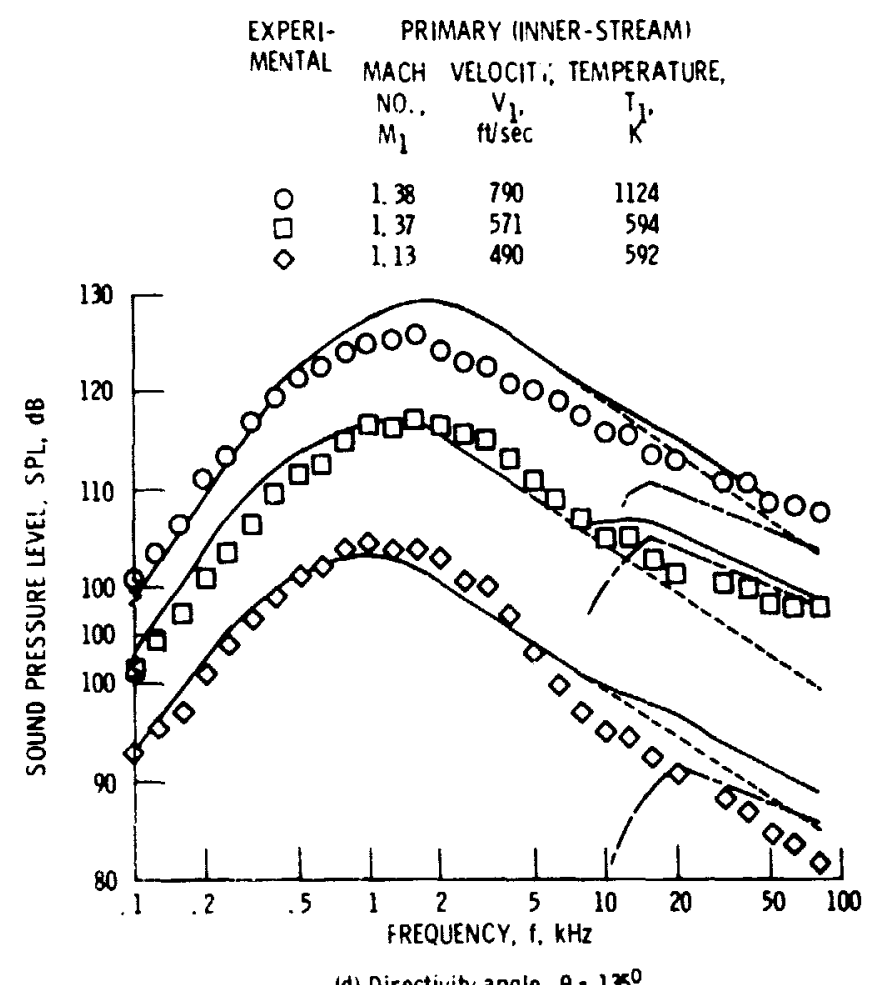

(d) Directivity angle, $\theta=135^{\circ}$.

Figure 14 - Continued. 


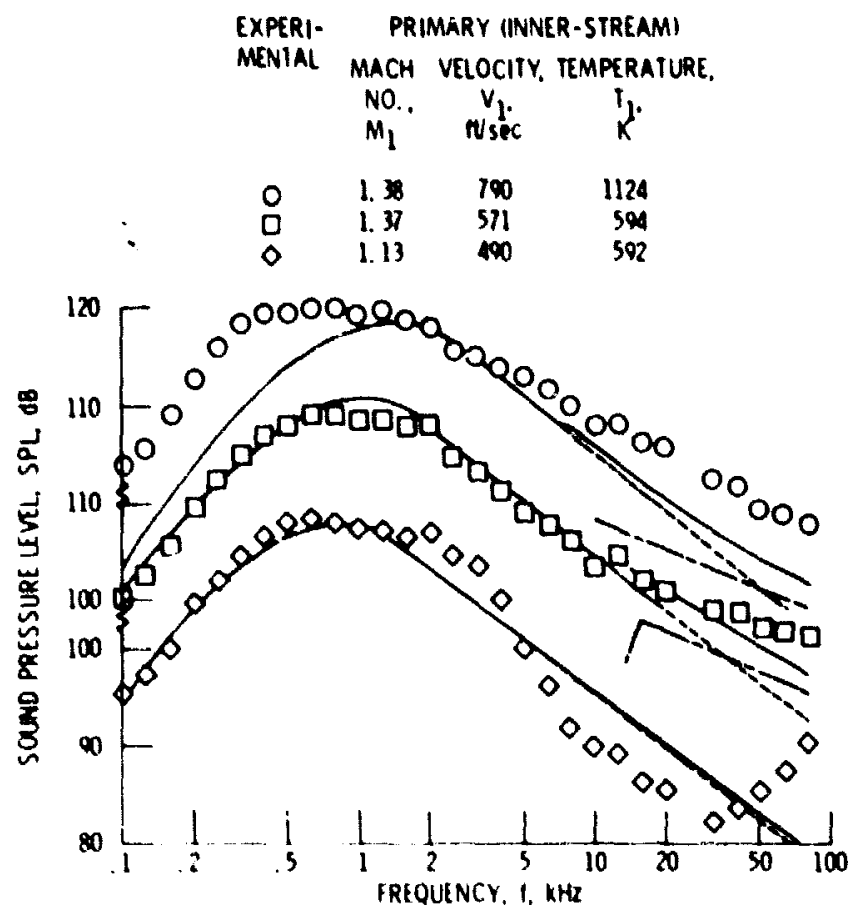

(e) Directivity angle, $\theta \cdot 150^{\circ}$

Flgure is - concluded. 

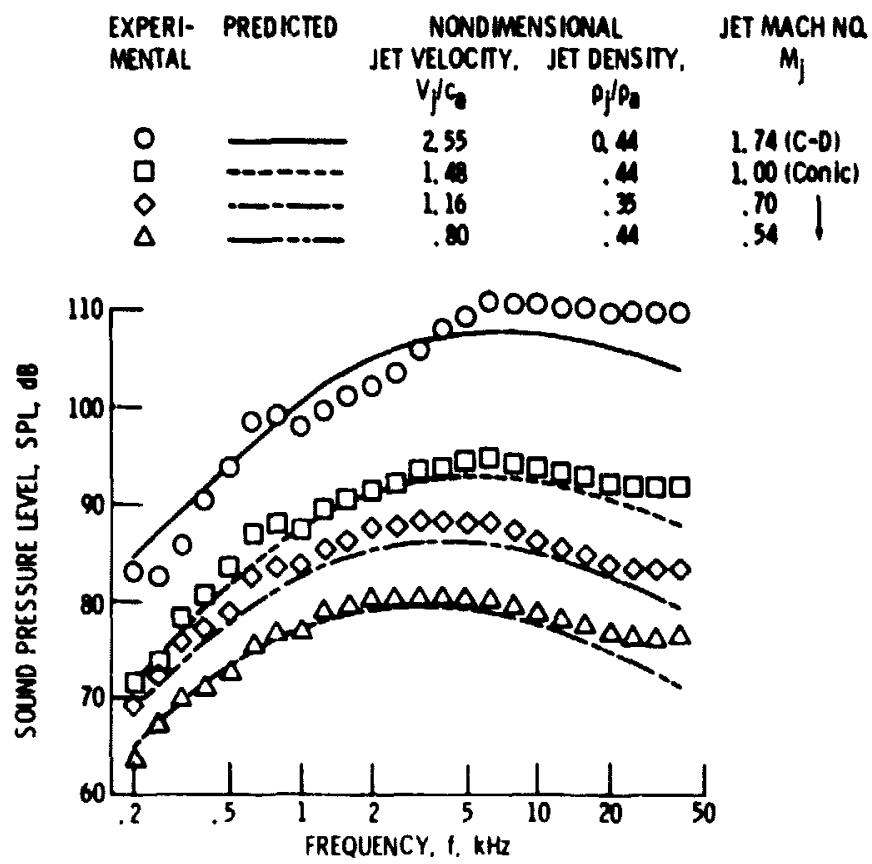

(a) Directivity angle, $\theta \cdot 57^{\circ}$

Figure Al. - Comparison of predicted and experimental effect of singlestrem jet conditions on lossless ir ee-field shock -free spectra on a $3.66-\mathrm{m}$ arc Experimental datu of Tanns. et al. Irel. 13 ) for $5.09-\mathrm{cm}$ diameter conical and circular convergent divergent nazzles.

EXPERI- PREDICIED MENTAL
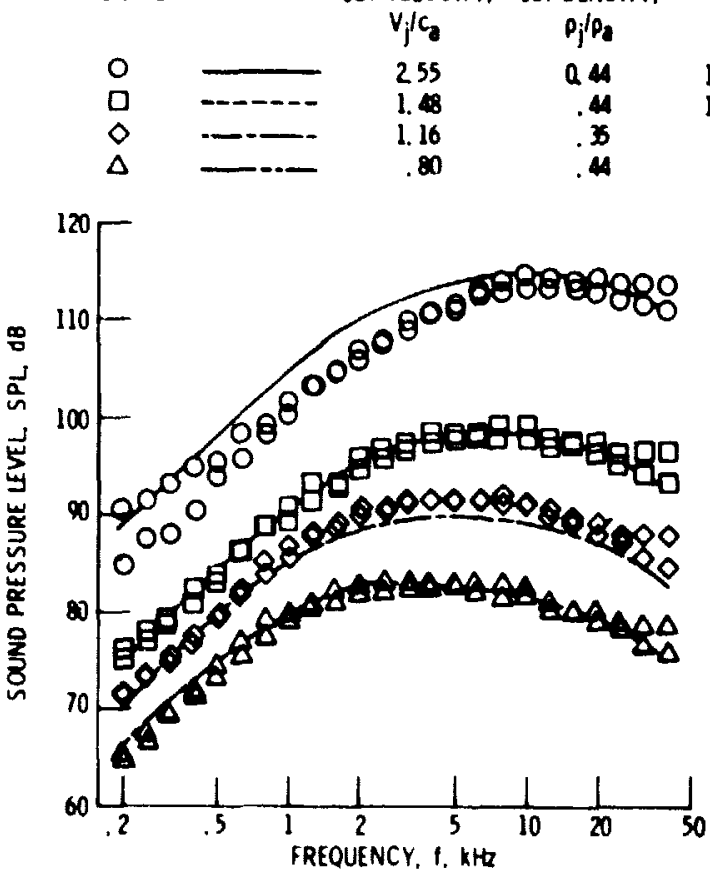

(b) Directivity angle, $\theta-8^{\circ}$.
JET MUCH NO.

$M_{j}$

$1.74(C-D)$
$1.00(C o n i c)$
.70
.54

Figure Al. - Continuert. 


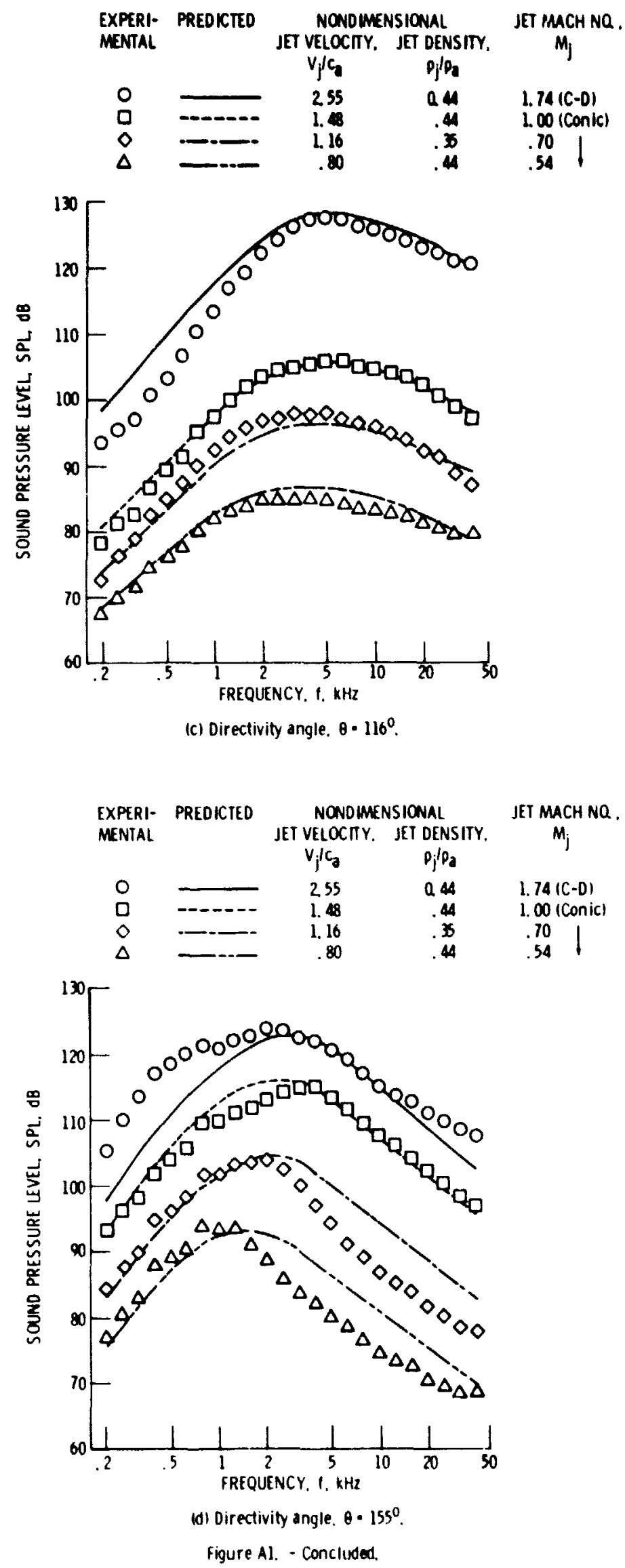



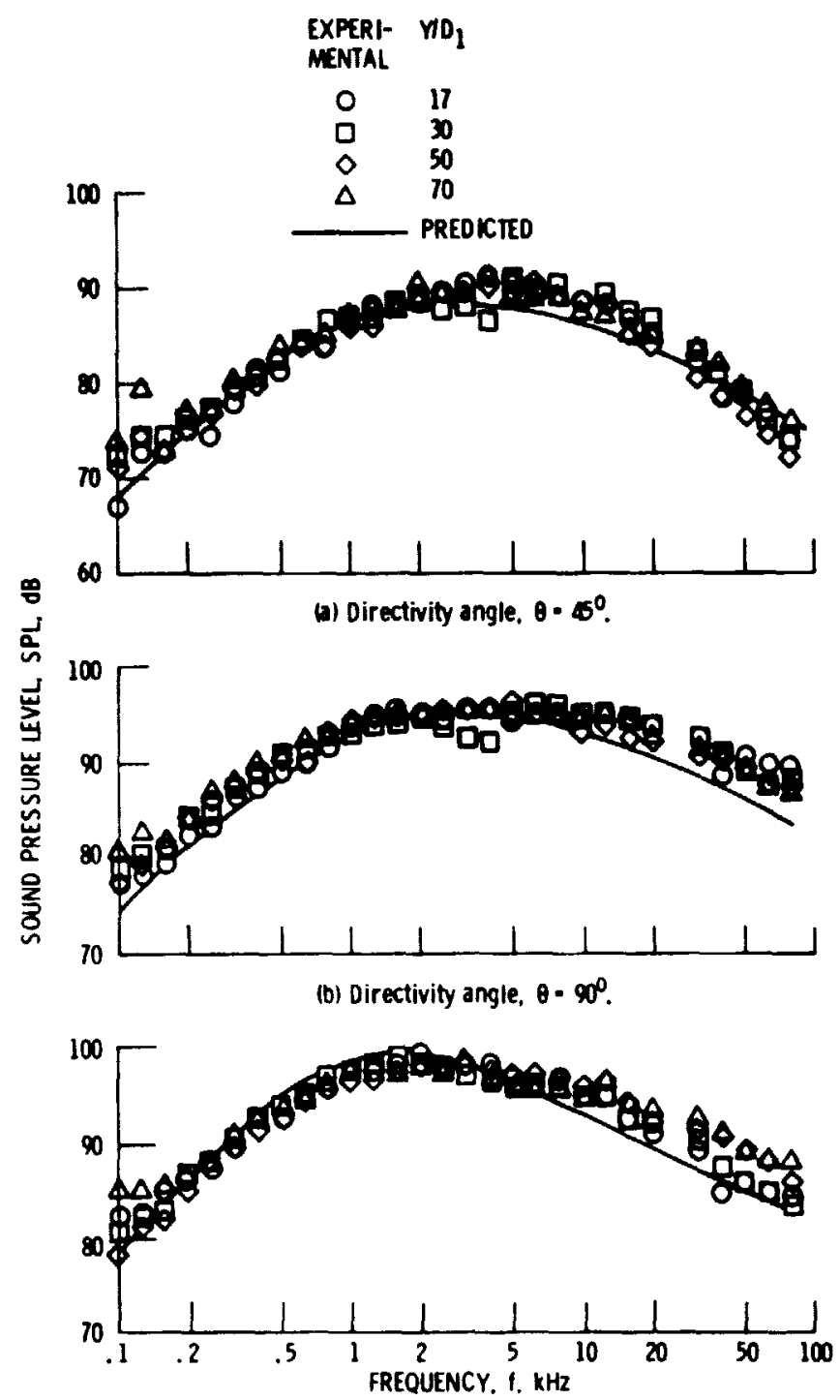

(c) Directivity angle, $\theta-15^{\circ}$.

Figure A2 - Comparison of prediction with lossless free-field experimental dat scaled to 3.0-m (9.8-ft) sideline for 3.2-area -ratio coplanar coixial nozzle. Inner-stream velocity, $V_{1}=28 \mathrm{~m} / \mathrm{sec}$ $(\$ 07 \mathrm{Hsec})$, and temperature $T_{1} \approx 287 \mathrm{~K} 517^{\circ} \mathrm{R}$, outer -stream (no flow).

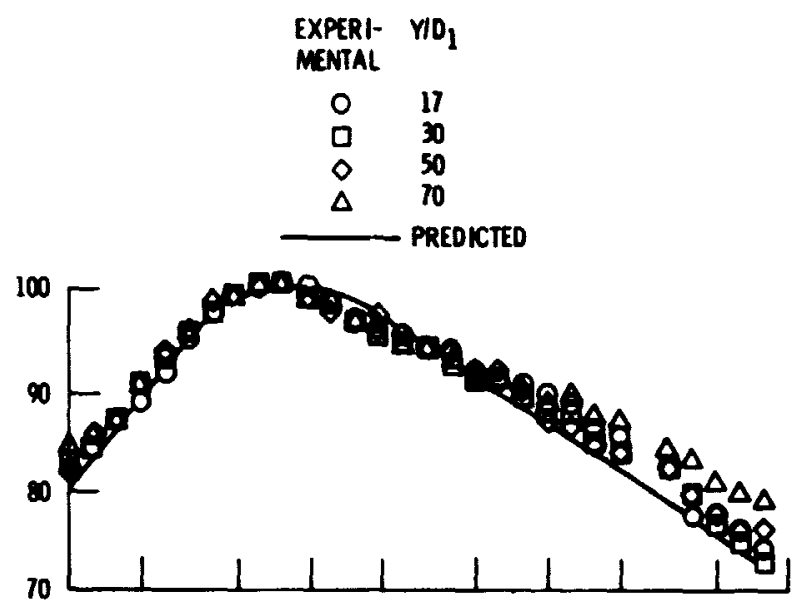

(d) Directivity angle, $0 \cdot 10^{\circ}$.
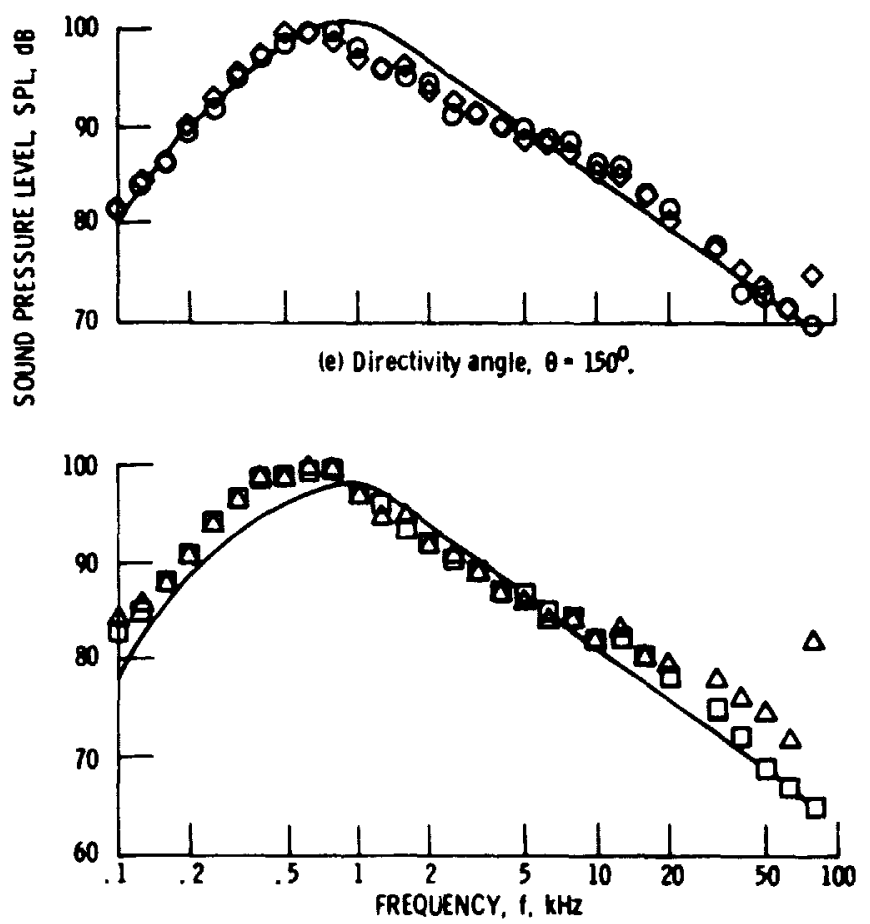

(i) Directivity angle, $\theta \cdot 155^{\circ}$.

Figure A2 - Concluded. 